NBER WORKING PAPER SERIES

\title{
GROWTH, TRADE, AND INEQUALITY
}

Gene M. Grossman

Elhanan Helpman

Working Paper 20502

http://www.nber.org/papers/w20502

\author{
NATIONAL BUREAU OF ECONOMIC RESEARCH \\ 1050 Massachusetts Avenue \\ Cambridge, MA 02138 \\ September 2014
}

We are grateful to Kirill Borusyak, Lior Galo, and Chang Sun for research assistance, as well as Pol Antràs and Thomas Sampson for comments. The views expressed herein are those of the authors and do not necessarily reflect the views of the National Bureau of Economic Research.

NBER working papers are circulated for discussion and comment purposes. They have not been peerreviewed or been subject to the review by the NBER Board of Directors that accompanies official NBER publications.

(C) 2014 by Gene M. Grossman and Elhanan Helpman. All rights reserved. Short sections of text, not to exceed two paragraphs, may be quoted without explicit permission provided that full credit, including (C) notice, is given to the source. 
Growth, Trade, and Inequality

Gene M. Grossman and Elhanan Helpman

NBER Working Paper No. 20502

September 2014

JEL No. D33,F12,F16,O41

\section{$\underline{\text { ABSTRACT }}$}

We introduce firm and worker heterogeneity into a model of innovation-driven endogenous growth. Individuals who differ in ability sort into either a research sector or a manufacturing sector that produces differentiated goods. Each research project generates a new variety of the differentiated product and a random technology for producing it. Technologies differ in complexity and productivity, and technological sophistication is complementary to worker ability. We study the co-determination of growth and income inequality in both the closed and open economy, as well as the spillover effects of policy and conditions in one country to outcomes in others.

Gene M. Grossman

International Economics Section

Department of Economics

Princeton University

Princeton, NJ 08544

and NBER

grossman@princeton.edu

Elhanan Helpman

Department of Economics

Harvard University

1875 Cambridge Street

Cambridge, MA 02138

and NBER

ehelpman@harvard.edu 


\section{Introduction}

The relationship between growth and inequality has been much studied and much debated. Scholars have advanced a number of hypotheses linking growth to inequality, with causation running in one direction or the other. Yet attempts to substantiate the proposed mechanisms and to measure their empirical relevance have been stymied by inadequate data and methodological pitfalls. Kuznets (1955, 1963), for example, famously advanced the hypothesis that income inequality first rises then falls over the course of economic development. While the "Kuznets curve" - an inverted-U shaped relationship between inequality and stage of development - has been established for the small set of countries that Kuznets considered, subsequent studies using broader data sets cast doubt on the ubiquity of this relationship. ${ }^{1}$

Inequality might affect growth via several channels, such as if rich and poor households differ in their propensity to save (Kaldor, 1955-56), if poor households face credit constraints that limit their ability to invest in human capital (Galor and Zeira, 1993), or if greater inequality generates more redistribution and thus a different incentive structure via the political process (Alesina and Rodrik, 1994; Persson and Tabellini, 1994). While all of these mechanisms are plausible, quantitative assessment has proven elusive due to the fact that a country's growth rates and income inequality are jointly determined. A similar problem has plagued attempts to assess the relationship between trade and growth (see Helpman, 2004, ch.6).

The historical record shows rising inequality in the distribution of personal income in the world economy from the early part of the 19th century - when growth accelerated after the industrial revolution - until well into the 20th century. The evolution of income inequality during this period reflects trends in within-country inequality and trends in between-country inequality. Table 1, drawn from Bourguignon and Morrisson (2002) and Morrisson and Murtin (2011a), provides a decomposition of these long-run trends, using the Theil Index as a measure of per capita income inequality. $^{2}$ The table shows that between-country inequality has risen over time throughout the course of almost two centuries, while the time path for within-country inequality has been more uneven. Such inequality rose steadily between 1820 and World War I, declined through the Great Depression and into the 1970's, and rose again subsequently. ${ }^{3}$ During the same period, growth in world per capita income accelerated until World War I, declined between the two world wars, and accelerated again after World War II, up until the oil crisis of 1973 (see Maddison, 2001). The first and second waves of globalization roughly correspond with the periods of rapid growth. It appears

\footnotetext{
${ }^{1}$ See Helpman (2004, ch.4) for a survey of this evidence.

${ }^{2}$ The normalized Theil Index $I$ for a set of income levels $\left\{y_{i}\right\}, i=1, \ldots, N$, is defined by

$$
I=\frac{1}{N \ln N} \sum_{i=1}^{N}\left[\frac{y_{i}}{\bar{y}} \ln \left(\frac{y_{i}}{\bar{y}}\right)\right]
$$

where $\bar{y}$ is the mean of $y$. It ranges from zero, when all incomes are the same, to one, when one individual enjoys all of the aggregate income.

${ }^{3}$ Sala-i-Martin (2006) reports further increases in within-country inequality as measured by the Theil Index for the period from 1992 to 2000, but declining between-country inequality, mostly due to rapid growth in China and India.
} 
Table 1: Income Inequality Within and Between Countries

Source: Bourguignon and Morrisson (2002) and Morrisson and Murtin (2011a)

\begin{tabular}{|l|c|c|}
\cline { 2 - 3 } \multicolumn{1}{c|}{} & \multicolumn{2}{c|}{ Theil Index of Income Inequality } \\
\cline { 2 - 3 } \multicolumn{1}{c|}{} & Within Countries & Between Countries \\
\hline 1700 & 0.45 & 0.04 \\
1820 & 0.46 & 0.05 \\
1870 & 0.48 & 0.19 \\
1910 & 0.50 & 0.30 \\
1929 & 0.41 & 0.37 \\
1960 & 0.32 & 0.46 \\
1980 & 0.33 & 0.50 \\
1992 & 0.34 & 0.54 \\
2000 & 0.35 & 0.51 \\
2008 & 0.36 & 0.39 \\
\hline
\end{tabular}

Figure 1: Growth versus change in inequality in a cross-section of countries.

Source: Morrisson and Murtin (2011b)

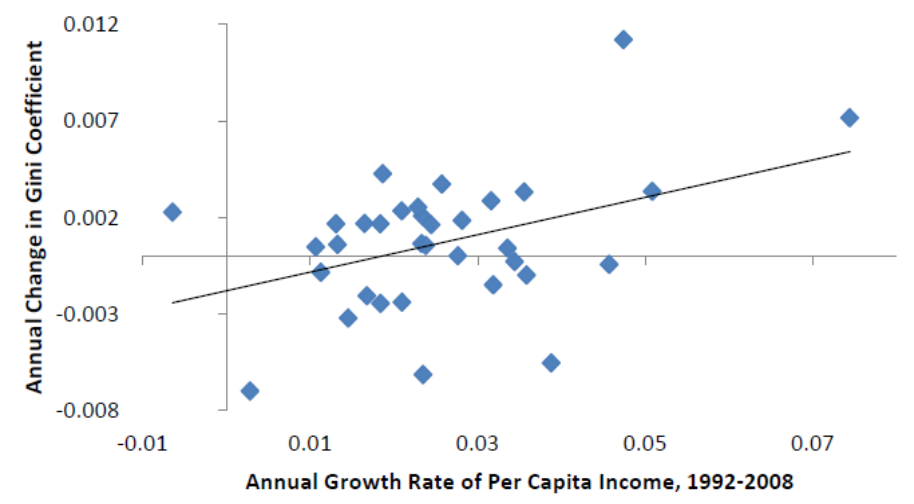

that at a broad, historical level, trade, growth and inequality have been positively correlated.

In more recent data, a link between growth and income inequality can be seen in a cross section of countries using the data reported by Morrisson and Murtin (2011b). They tabulate the Gini coefficients of disposable income for 35 countries at varying stages of development, for a pair of years chosen based on data availability. Typically, the first observation for each country is for a year in the early 1990's and the second is for a year in the mid-2000's. As well, they report real GDP per inhabitant in 1992 and in 2008. In Figure 1, we plot the annual growth rate in per capita income against the percentage change in the Gini coefficient per annum for these 35 countries. The positive correlation between the two measures is quite apparent.

The aim of this paper is to explore theoretically the relationship between long-run growth and income inequality and to understand the role that international integration plays in mediating this relationship. ${ }^{4}$ To this end, we introduce worker and firm heterogeneity into a familiar model of

\footnotetext{
${ }^{4}$ Because we are interested in long-run growth and income inequality, we will focus our analysis on balanced growth
} 
endogenous growth à la Romer (1990). Here, the accumulation of knowledge serves as the engine of growth and is itself a by-product of purposive innovation undertaken to develop new products. Our model of trade, international knowledge diffusion, and growth extends the simplest, one-sector model from Grossman and Helpman (1991). ${ }^{5}$ The advantage of the framework we develop here is that it allows us to consider the entire distribution of earnings that emanates from a given distribution of worker abilities and firm productivity levels, and not just, say, the skill premium (i.e., the relative wage of "skilled" versus "unskilled" workers), which has been the focus of much of the existing theoretical literature.

Our analysis provides potential explanations for cross-differences in wage distributions and generates predictions about how technology and policy changes will affect wages at different points in the distribution and measures of aggregate income inequality. ${ }^{6}$ Our interest in the entirety of the wage distribution reflects our understanding that distributions vary considerably across countries and over time. Take, for example, Table 2, which displays the ratio of the fifth decile of men's earnings to the bottom decile of earnings and the ratio of the ninth decile of men's earnings to the fifth decile of earnings for two different years and ten different OECD countries. ${ }^{7}$ In the first column of the table, we see that middle-income male earners fared much better in the United States compared to the bottom-tier workers than did their counterparts in France, yet the earnings of this group compared to the top-decile workers was about the same. The distribution in Canada was notably different from that in France, with a high ratio of fifth decile relative to first decile wages, but a more modest ratio of ninth decile wages relative to fifth decile.

The table shows as well that countries have experienced different changes over time. In some, like Ireland, Japan and Norway, wage inequality seems to have increased at both the bottom of the distribution (increase in the earnings of the fifth decile relative to the first decile) and at the top (increase in the earnings of the ninth decile relative to the fifth decile). In Canada and the United Kingdom, there was little change at the bottom end but a notable increase in equality at the top, whereas the pattern was just the opposite in Germany. Finally, in France, inequality declined modestly at both ends of the distribution.

Data on the U.S. income distribution are available for a longer span of time. Kopczuk et al. (2010) use social security records to establish U-shaped patterns for the evolution from 1939 to 2004 of the ratio of the 80th to 50th percentile male earner and the ratio of the 50th to 20th

paths. As such, we will not be able to speak directly to the data illustrated in Figure 1, which arguably related to transition paths in most of the countries in the sample.

${ }^{5}$ In Grossman and Helpman (1991), we devote several chapters to models with two or more industrial sectors in order to address the impact of intersectoral resource allocation on growth and relative factor prices. By considering here a model with one industrial sector, we neglect this important, additional channel for trade to influence growth and income distribution.

${ }^{6}$ Note, however, that our framework does not include a role for "superstars" and so is ill-suited to speak to evidence such as that emphasized by Atkinson et al. (2011) that income shares have been growing dramatically of late at the very top end of the distribution.

${ }^{7}$ We focus on men's earnings, because we have nothing to say about the substantial cross-country differences in female labor-market participation rates. We report observations for 2000 and 2007, because the former are the earliest available in the OECD data set and the latter are the latest that do not reflect the impact of the financial crisis and resulting Great Recession. 
Table 2: Earnings Inequality in OECD Countries

Source: OECD StatExtracts. Accessed on February 28, 2014

\begin{tabular}{|l|c|c|c|c|}
\cline { 2 - 5 } \multicolumn{1}{c|}{} & \multicolumn{2}{c|}{2000} & \multicolumn{2}{c|}{2007} \\
\cline { 2 - 5 } \multicolumn{1}{c|}{} & Decile 5/Decile 1 & Decile 9/Decile 5 & Decile 5/Decile 1 & Decile 9/Decile 5 \\
\hline Canada & 2.00 & 1.74 & 2.00 & 1.81 \\
France & 1.56 & 2.11 & 1.52 & 2.09 \\
Germany & 1.65 & 1.82 & 1.78 & 1.82 \\
Ireland & 1.81 & 1.89 & 1.94 & 1.98 \\
Japan & 1.59 & 1.73 & 1.62 & 1.77 \\
Korea & 1.97 & 1.88 & 2.21 & 2.13 \\
Norway & 1.44 & 1.50 & 1.58 & 1.55 \\
Sweden & 1.40 & 1.74 & 1.42 & 1.72 \\
UK & 1.83 & 1.89 & 1.83 & 2.02 \\
U.S.A. & 2.14 & 2.24 & 2.15 & 2.40 \\
\hline
\end{tabular}

Figure 2: Evolution of inequality in the United States Source: Kopczuk et al. (2010)

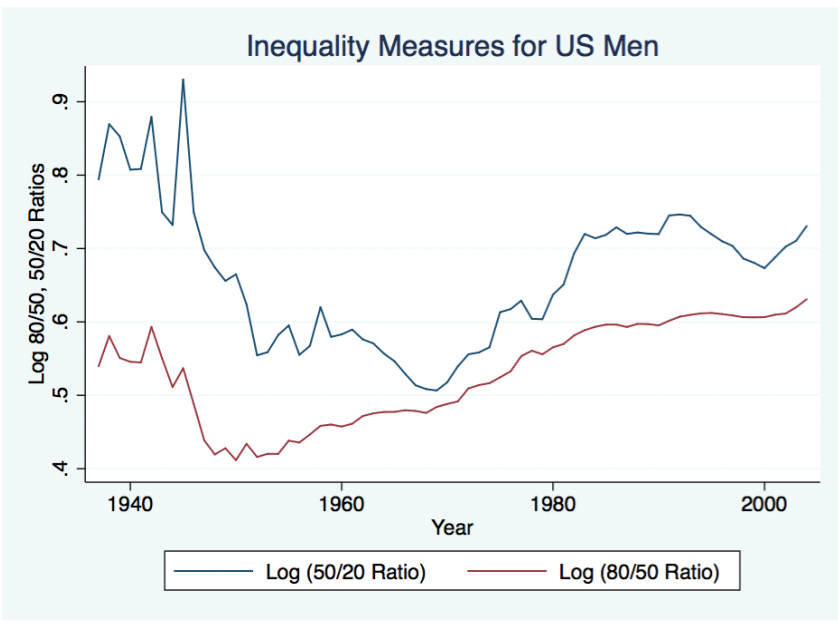

percentile male earner (see Figure 2). Both ratios fell until the early-to-mid 1950's and generally rose after 1970. However, the 1960s and 1990s were periods of a declining relative wage for the median male earner compared to both the 80th and 20th percentile earner; Autor (2010) refers to the latter period as one of "hollowing out of the middle class." While the intention of this paper is not to offer explanations for the observed differences across space and across time, the variation in outcomes and experiences do motivate our interest in the determinants of the earnings profile. We shall see that our model can generate diverse patterns across countries and provides a link between income distribution and the economy's structural and policy features.

In the next section, we develop our model in the context of a closed economy. A country is populated by heterogeneous individuals who differ in ability. The economy produces a single consumption good with differentiated intermediate inputs. Blueprints for the intermediate goods are 
the result of prior innovation efforts and are held by firms that engage in monopolistic competition. These firms have access to different technologies and can hire workers of any ability. A firm's total output is the sum of the outputs of its various employees and the productivity of any employee depends on his ability and on the firm's technology. Moreover, ability and technology are complementary, so that more able workers are especially productive when they apply more sophisticated technologies. In equilibrium, the firms with access to the better technologies hire the more able workers.

Innovation drives growth. Firms invest in R\&D by hiring individuals to serve as inventors. An inventor develops new varieties at a rate that depends on his own ability and the stock of knowledge capital available in the economy. Knowledge accumulates with R\&D experience and is non-proprietary, as in Romer (1990). When an inventor develops a new variety, the invention generates for the firm a draw from a distribution of technologies. Thus, returns to investment in $R \& D$ are random and higher for firms that are lucky enough to draw good (sophisticated) technologies than for firms that draw less good (simple) technologies. There is free entry into $\mathrm{R} \& \mathrm{D}$, so at every moment with positive innovation, the momentary cost of a new variety in light of the state of knowledge matches the expected present discounted value of profits that will result from the random technology draw.

Since firms make zero expected returns and firm ownership is shared widely, the (pre-tax) income distribution is determined in the competitive labor market. The heterogenous individuals sort into the research and manufacturing activities. We assume that ability confers a comparative advantage in $\mathrm{R} \& \mathrm{D}$ and describe an equilibrium in which all individuals with ability above some endogenous cutoff level engage in research. For those who choose to work in manufacturing, there is competition among the firms that produce intermediate goods with different technologies. The complementarity between ability and technology delivers positive assortative matching. These competitive forces of sorting and matching dictate the economy's wage distribution.

After developing the model, we show how the long-run growth rate and income distribution are co-determined in a steady-state equilibrium. More specifically, we derive a pair of equations that jointly determine the time-invariant growth rate in the number of varieties and the cutoff ability level that divides manufacturing workers from inventors. Once we know the rate of growth in the variety of intermediate goods, we can calculate the rate of growth of final output and the rate of growth of wages. Once we know the cutoff ability level, we can calculate (as we show) the entire distribution of relative wages. We conclude Section 2 by discussing how different income distributions can be compared and adopt an ordinal ranking of inequality that is scale invariant and respects second-order stochastic dominance. ${ }^{8}$

In Section 3, we compare growth rates and income inequality across countries that differ in their technological parameters and policy choices. In this section, we focus on isolated countries that do not trade and do not benefit from any knowledge spillovers from abroad. We find, for example,

\footnotetext{
${ }^{8}$ Specifically, we shall say that one income distribution is more unequal than another if after adjusting one distribution by a proportional shift to equate mean wages, the former distribution represents a mean-preserving spread of the latter.
} 
that Hicks-neutral differences in labor productivity in manufacturing that apply across the full range of ability levels do not generate long-run differences in growth rates or income inequality, although they do imply differences in income and consumption levels. In contrast, differences in "innovation capacity" do generate differences in growth and inequality. Innovation capacity is the product of a parameter that measures the size of a country's labor force, a parameter that reflects its ability to convert research experience into knowledge capital, and a parameter that reflects inventor's productivity in $\mathrm{R} \& \mathrm{D}$. A country with greater innovation capacity grows faster in autarky but experiences greater income inequality. Subsidies to R\&D financed by proportional wage taxes also contribute to faster growth but greater inequality. Finally, we compare countries that differ in the set of production technologies from which their successful innovators draw. We show that better technology draws can generate an income distribution with higher relative wages in the middle relative to both extremes.

Section 4 addresses the impacts of globalization. Here, intermediate inputs are tradable subject to arbitrary iceberg trading costs and import tariffs. We follow Grossman and Helpman (1991) by introducing international sharing of knowledge capital and, in fact, allow for an arbitrary pattern of (positive) international spillovers. In particular, the knowledge stock in each country is a weighted sum of accumulated $\mathrm{R} \& \mathrm{D}$ experience in all countries including itself, with an arbitrary matrix of weighting parameters. We study a balanced-growth equilibrium in which the number of varieties of intermediate goods grows at the same constant rate in all countries. Even allowing for a wide range of differences in technologies and policies, we find that the long-run growth rate is higher in every country in the trading equilibrium than in autarky, but so too is the resulting inequality in incomes. Neither differences in manufacturing productivity, in trade frictions, or in innovation capacity generate long-run differences in income inequality. In fact, no matter what the pattern of international knowledge spillovers, if $R \& D$ subsidies are the same in a pair of countries and their inventors draw from the same technology distributions, their relative-wage distributions will converge in the long-run. ${ }^{9}$ Differences in support for $\mathrm{R} \& \mathrm{D}$ do give rise to long-run differences in wage inequality, as a higher subsidy goes hand in hand with a greater spread in wages. Also, if inventors in different countries draw from different technology sets, their income distributions will differ in the long run. We identify conditions under which a country that draws from a better set of technologies has greater inequality at the lower end of the income distribution, but similar or less inequality at the upper end. In Section 4, we also examine how various policy and parameter changes affect long-run growth and inequality measures in the open economy both at home and abroad. For example, we show that an increase in the R\&D subsidy rate in any country accelerates growth and raises inequality in all of them, as does an improvement in a country's ability to absorb knowledge spillovers from abroad.

Section 5 concludes and an appendix contains supporting technical details.

\footnotetext{
${ }^{9}$ Note, however, that the levels of all wages can vary across countries to reflect local conditions.
} 


\section{The Basic Model}

In this section, we develop a model of economic growth featuring heterogeneous workers and heterogeneous firms. In the model, endogenous innovation drives growth. Workers, who differ in ability, engage either in R\&D or in manufacturing. Research generates new varieties of differentiated intermediate inputs. Firms that produce these inputs operate different technologies. In the equilibrium, the heterogeneous workers sort into one of the two activities and firms with different technologies hire different types of workers. The economy converges to a long-run equilibrium with a constant growth rate of final output and a fixed and continuous distribution of income.

We describe here the economic environment for a closed economy and defer the introduction of international trade until Section 4.

\subsection{Demand and Supply for Consumption Goods}

The economy is populated by a mass $N$ of individuals indexed by ability level, $a$. The cumulative distribution of abilities is given by $H(a)$, which is twice continuously differentiable and has a positive density $H^{\prime}(a)>0$ on the bounded support, [ $\left.a_{\min }, a_{\max }\right]$.

Each individual maximizes a logarithmic utility function

$$
u_{t}=\int_{t}^{\infty} e^{-\rho(\tau-t)} \log c_{\tau} d \tau
$$

where $c_{\tau}$ is consumption at time $\tau$ and $\rho$ is the common, subjective discount rate. The consumption good serves as numeraire; its price at every moment is normalized to one. It follows from the individual's intertemporal optimization problem that

$$
\frac{\dot{c}_{t}}{c_{t}}=\iota_{t}-\rho
$$

where $\iota_{t}$ is the interest rate at time $t$ in terms of consumption goods. Inasmuch as $a$ varies across individuals, so does income and consumption.

Consumption goods are assembled from an evolving set $\Omega_{t}$ of differentiated intermediate inputs. Dropping the time subscript for notational convenience, the production function for these goods at a moment when the set of available inputs is $\Omega$ is given by

$$
X=\left[\int_{\omega \in \Omega} x(\omega)^{\frac{\sigma-1}{\sigma}} d \omega\right]^{\frac{\sigma}{\sigma-1}}, \quad \sigma>1,
$$

where $x(\omega)$ is the input of variety $\omega$. The elasticity of substitution between intermediate inputs is constant and equal to $\sigma$.

The market for consumption goods is competitive. It follows that the equilibrium price of these 
goods reflects the minimum unit cost of producing them. Since $X$ is the numeraire, we have

$$
\left[\int_{\omega \in \Omega} p(\omega)^{1-\sigma} d \omega\right]^{\frac{1}{1-\sigma}}=1
$$

where $p(\omega)$ is the price of intermediate input $\omega$.

\subsection{Supply, Demand, Pricing, and Profits of Intermediate Goods}

Once an intermediate good has been invented, it is produced by monopolistically-competitive firms using labor as the sole input. Firms that manufacture these goods are distinguished by their technology, $\varphi$. A firm with a higher $\varphi$ is more productive, no matter what type(s) of workers it hires. Consider a firm that produces variety $\omega$ using technology $\varphi$ and that hires a set $L_{\omega}$ of workers types with densities $\ell_{\omega}(a)$. In such circumstances, the firm's output is

$$
x(\omega)=\int_{a \in L_{\omega}} \psi(\varphi, a) \ell_{\omega}(a) d a
$$

where $\psi(\varphi, a)$ is the productivity of workers of type $a$ when applying technology $\varphi$. Notice that productivity (given $\varphi$ ) is independent of $\omega$.

We suppose that more productive technologies are also more complex and that more able workers have a comparative advantage in operating the more complex technologies. In other words, we posit a complementarity between the type of technology $\varphi$ and the type of worker $a$ in determining labor productivity. Formally, we adopt

Assumption 1 The productivity function $\psi(\varphi, a)$ is twice continuously differentiable, strictly increasing, and strictly log supermodular.

Assumption 1 implies $\psi_{\varphi a}>0$ for all $\varphi$ and $a$.

As is known from Costinot (2009), Eeckhout and Kircher (2013), Sampson (2013) and elsewhere, the strict log supermodularity of $\psi(\cdot)$ implies that, for a generic wage schedule $w(a)$, each manufacturing firm hires a single type of labor that is most appropriate given its technology $\varphi$, and there is positive assortative matching (PAM) between firm types and worker types. We denote by $m(\varphi)$ the ability of workers employed by all firms that produce a variety of intermediate by operating a technology $\varphi$; PAM is revealed in the fact that $m^{\prime}(\varphi)>0$.

Shephard's lemma gives the demand for any variety $\omega$ as a function of the prices of all available intermediate goods, namely

$$
x(\omega)=X\left[\int_{v \in \Omega} p(v)^{1-\sigma} d v\right]^{\frac{\sigma}{1-\sigma}} p(\omega)^{-\sigma} .
$$

In view of (4), demand for variety $\omega$ can be expressed as

$$
x(\omega)=X p(\omega)^{-\sigma} \text { for all } \omega \in \Omega .
$$


Each firm takes aggregate output of final goods $X$ as given and so it perceives a constant elasticity of demand, $-\sigma$. As is usual in such settings, the profit-maximizing firm applies a fixed percentage markup to its unit cost.

Considering the optimal hiring decision, a firm that operates a technology $\varphi$ has productivity $\psi[\varphi, m(\varphi)]$ and pays a wage $w[m(\varphi)]$. Hence, the firm faces a minimal unit cost of $w[m(\varphi)] / \psi[\varphi, m(\varphi)]$. The firm's profit-maximizing price is given by ${ }^{10}$

$$
p(\varphi)=\left(\frac{\sigma}{\sigma-1}\right) \frac{w[m(\varphi)]}{\psi[\varphi, m(\varphi)]}
$$

This yields an operating profit of

$$
\pi(\varphi)=\sigma^{-\sigma}(\sigma-1)^{-(\sigma-1)} X\left\{\frac{w[m(\varphi)]}{\psi[\varphi, m(\varphi)]}\right\}^{1-\sigma} .
$$

\subsection{Inventing New Varieties}

An entrepreneur can develop a new variety of intermediate input at any time. As in Romer (1990), we treat $R \& D$ as an up-front, fixed cost. The productivity of labor in the R\&D activity depends on the ability of the research worker and the state of knowledge in the economy. We measure the knowledge stock at time $t$ by $\theta_{K} M_{t}$, where $M_{t}$ is the mass of varieties that have been developed before time $t$ and $\theta_{K}$ is a parameter that reflects how effectively the economy converts cumulative research experience into applicable knowledge.

Consider $\ell_{R}(a)$ workers with abilities in the interval $[a, a+d a]$ who engage in research when the stock of knowledge is $\theta_{K} M$. These workers expand the set of available varieties by $d M=$ $\theta_{K} M T(a) \ell_{R}(a) d a$ per unit time, where $T(a)$ is an increasing function that captures how worker ability translates into R\&D productivity. In equilibrium, the set $L_{R}$ of worker types performs the research function, with density $\ell_{R}(a)$. Then growth in the measure of varieties is given by

$$
g_{M}=\theta_{K} N \int_{a \in L_{R}} T(a) \ell_{R}(a) d a
$$

where $g_{M}=\dot{M} / M$.

Each invention generates a technology for producing a new variety. As in Melitz (2003), we assume that entrepreneurs learn their technology only after the good is invented. Beforehand, they perceive that $\varphi$ will be drawn from a cumulative distribution function $G(\varphi)$ that is strictly increasing and twice continuously differentiable on the bounded support $\left[\varphi_{\min }, \varphi_{\max }\right]$.

Entrepreneurs can enter freely into R\&D. Entry at time $t$ generates a draw from the technology distribution $G(\varphi)$ and then a stream of operating profits, $\pi_{\tau}(\varphi)$ for $\tau \geq t$. On a balanced-growth path, wages of all types of workers grow at the common rate $g_{w}$ and final output grows at a constant rate $g_{X}$. Final output serves only consumption, so, by $(2), g_{X}=\iota-\rho$. Operating profits also grow

\footnotetext{
${ }^{10}$ We henceforth index intermediate goods by the technology with which they are produced $(\varphi)$ rather than their variety name $(\omega)$, since all varieties are symmetric except for their different technologies.
} 
at a constant rate $g_{\pi}$, independent of $\varphi$, and, by (8), $g_{\pi}=g_{X}-(\sigma-1) g_{w}$. Finally, (4) and (7) imply that, in a steady state, $(\sigma-1) g_{w}=g_{M}$. Combining these long-run relationships, the expected discounted profits for a new entrant at time $t$ can be written as

$$
\int_{t}^{\infty} e^{-\iota(\tau-t)} \int_{\varphi_{\min }}^{\varphi_{\max }} \pi_{\tau}(\varphi) d G(\varphi) d \tau=\frac{\int_{\varphi_{\min }}^{\varphi_{\max }} \pi_{t}(\varphi) d G(\varphi)}{\rho+g_{M}}
$$

With free entry, this must equal the cost of developing a new variety, $w(a) / T(a) \theta_{K} M_{t}$ for any $a \in L_{R}$. We again drop the time subscript and write the steady-state free-entry condition as

$$
\frac{\int_{\varphi_{\min }}^{\varphi_{\max }} \pi(\varphi) d G(\varphi)}{\rho+g_{M}}=\frac{w(a)}{T(a) \theta_{K} M} \text { for all } a \in L_{R} .
$$

\subsection{Sorting, Matching, and Labor-Market Equilibrium}

Individuals gain employment in either research or manufacturing. We assume that high-ability individuals enjoy a comparative advantage in R\&D. In particular, we adopt

Assumption 2 The ratio $T(a) / \psi(\varphi, a)$ is increasing in $a$ for all $\varphi \in\left[\varphi_{\min }, \varphi_{\max }\right]$ and all $a \in$ $\left[a_{\min }, a_{\max }\right]$.

As we shall see in a moment, this assumption suffices to ensure that, in an equilibrium with positive growth, all of the best workers with $a$ greater than some $a_{R}$ engage in R\&D, while the remaining workers with $a$ less than $a_{R}$ manufacture intermediate goods.

Consider the competitive wages paid to any set of workers employed in the manufacturing sector. In equilibrium, these wages must be such that the firm with productivity $\varphi$ is willing to hire the worker with ability $m(\varphi)$ and does not prefer to hire instead a different worker. In other words, the wage function must be such that profits are maximized for a firm of type $\varphi$ when it chooses the worker of type $m(\varphi)$. From the first-order condition for cost minimization, we have ${ }^{11}$

Lemma 1 Consider any closed interval of workers $\left[a^{\prime}, a^{\prime \prime}\right]$ that is employed in the manufacturing sector in equilibrium. In the interior of this interval, the wage schedule must satisfy

$$
\frac{w^{\prime}(a)}{w(a)}=\frac{\psi_{a}\left[m^{-1}(a), a\right]}{\psi\left[m^{-1}(a), a\right]} \text { for all } a \in\left(a^{\prime}, a^{\prime \prime}\right),
$$

where $m^{-1}(\cdot)$ is the inverse of $m(\cdot)$.

Similarly, the entrepreneurs engaged in R\&D must be willing to hire all of the workers employed there. Potential entrepreneurs are homogeneous, so full employment requires that wages rise with productivity in research, i.e.,

\footnotetext{
${ }^{11}$ The cost-minimization problem for a firm with productivity $\varphi$ is to minimize $w(a) / \psi(\varphi, a)$. See also Sampson (2013) for further discussion and use of this wage formula.
} 
Lemma 2 Consider any closed interval of workers $\left[a^{\prime}, a^{\prime \prime}\right]$ that is employed in the R\&D sector in equilibrium. In the interior of this interval, the wage schedule must satisfy

$$
\frac{w^{\prime}(a)}{w(a)}=\frac{T^{\prime}(a)}{T(a)} \text { for all } a \in\left(a^{\prime}, a^{\prime \prime}\right)
$$

To secure full employment at all ability levels, the wage function must be continuous on $\left[a_{\min }, a_{\max }\right]$.

Now suppose that an ability level $a_{R}$ is a "cutoff" point such that an interval of workers with abilities just below $a_{R}$ works in one sector (i.e., manufacturing or R\&D) while an interval of workers with abilities just above $a_{R}$ works in the other. First note that the wage schedule $w(a)$ must be continuous at any such $a_{R}$; otherwise a firm that hires individuals with ability just above $a_{R}$ could save discretely by hiring slightly less able workers while sacrificing only marginally in the productivity of its workforce. Next, suppose that the workers with abilities in an interval $\left[a^{\prime}, a_{R}\right)$ are employed in $\mathrm{R} \& \mathrm{D}$ whereas those with abilities in the interval $\left(a_{R}, a^{\prime \prime}\right]$ are employed in manufacturing, for some $a^{\prime}<a_{R}<a^{\prime \prime}$. Considering the shape of the wage schedule dictated by Lemma 1, if Assumption 2 is satisfied, an entrepreneur could hire workers with ability slightly greater than $a_{R}$ to conduct research and would capture strictly positive expected profits. ${ }^{12}$ Of course, this is not possible in equilibrium, so the workers to the right of any cutoff point must in fact be employed in R\&D, not in manufacturing. In short, we have

Lemma 3 In any equilibrium with positive growth, all workers with type $a \in\left[a_{\min }, a_{R}\right)$ are employed in the manufacturing sector and all workers with type $a \in\left(a_{R}, a_{\max }\right]$ are employed in the $R \mathscr{E} D$ sector, for some $a_{R} \in\left(a_{\min }, a_{\max }\right)$.

Now that we know which workers are employed in each sector, we can derive a differential equation for the matching function in manufacturing by equating the supply of workers in some bottom interval of ability levels to the demand for workers by all firms that hire these workers. We express this condition in terms of the wage bill paid and received by employees of all firms with a

\footnotetext{
${ }^{12} \mathrm{~A}$ firm that hires the marginal researchers with ability $a_{R}$ to conduct R\&D pays a cost $c_{R}\left(a_{R}\right)$ per innovation, where $c_{R}\left(a_{R}\right)=w\left(a_{R}\right) / \theta_{K} M T\left(a_{R}\right)$. If the firm were instead to hire slightly better researchers, the proportional change in its cost per innovation would be

$$
\frac{c_{R}^{\prime}\left(a_{R}\right)}{c_{R}\left(a_{R}\right)}=\frac{w^{\prime}\left(a_{R}\right)}{w\left(a_{R}\right)}-\frac{T^{\prime}\left(a_{R}\right)}{T\left(a_{R}\right)} .
$$

Since we have hypothesized that individuals with $a \in\left[a_{R}, a^{\prime \prime}\right]$ are employed in manufacturing, the wage profile in this range is guided by Lemma 1. Accordingly,

$$
\frac{c_{R}^{\prime}\left(a_{R}\right)}{c_{R}\left(a_{R}\right)}=\frac{\psi_{a}\left[m^{-1}\left(a_{R}\right), a_{R}\right]}{\psi\left[m^{-1}\left(a_{R}\right), a_{R}\right]}-\frac{T^{\prime}\left(a_{R}\right)}{T\left(a_{R}\right)}<0,
$$

where the inequality follows directly from Assumption 2.
} 
technology index less than or equal to $\varphi$, namely ${ }^{13}$

$$
M X\left(\frac{\sigma}{\sigma-1}\right)^{-\sigma} \int_{\varphi_{\min }}^{\varphi}\left\{\frac{w[m(\phi)]}{\psi[\phi, m(\phi)]}\right\}^{1-\sigma} d G(\phi)=N \int_{a_{\min }}^{m(\varphi)} w(a) d H(a) .
$$

Differentiating this equation yields

$$
m^{\prime}(\varphi)=\frac{M X}{N}\left(\frac{\sigma}{\sigma-1}\right)^{-\sigma} \frac{w[m(\varphi)]^{-\sigma}}{\psi[\varphi, m(\varphi)]^{1-\sigma}} \frac{G^{\prime}(\varphi)}{H^{\prime}[m(\varphi)]} \text { for all } \varphi \in\left[\varphi_{\min }, \varphi_{\max }\right]
$$

We know from Grossman et al. (2013) that, given $a_{R}$, this equation together with the wage equation (11) applied for $a \in\left[a_{\min }, a_{R}\right]$ and the boundary conditions

$$
m\left(\varphi_{\min }\right)=a_{\min }, \quad m\left(\varphi_{\max }\right)=a_{R}
$$

uniquely determine the matching function and the wage function for workers in manufacturing. ${ }^{14}$ To emphasize the dependence of matching on the identity of the marginal worker, we will sometimes write the matching function as $m\left(\varphi ; a_{R}\right)$. Note that matching depends on the properties of the labor productivity function $\psi(\cdot)$, the distribution functions of firm and worker types $G(\cdot)$ and $H(\cdot)$, and the elasticity of substitution $\sigma$, because these features of the economic environment enter the differential equations. Matching does not depend directly on other parameters of the model, although these parameters can affect matching indirectly, if they alter the cutoff $a_{R}$. It is also clear that $M X / N$, which appears in (13), has no affect on matching; rather, changes in this measure of the size of the economy shift the wage function proportionately. This last point becomes particularly clear following differentiation of (13) and the derivation of a second-order differential equation for the matching function,

$$
\frac{m^{\prime \prime}(\varphi)}{m^{\prime}(\varphi)}=(\sigma-1) \frac{\psi_{\varphi}[\varphi, m(\varphi)]}{\psi[\varphi, m(\varphi)]}-\frac{\psi_{a}[\varphi, m(\varphi)] m^{\prime}(\varphi)}{\psi[\varphi, m(\varphi)]}+\frac{G^{\prime \prime}(\varphi)}{G^{\prime}(\varphi)}-\frac{H^{\prime \prime}[m(\varphi)] m^{\prime}(\varphi)}{H^{\prime}[m(\varphi)]}
$$

which is independent of $M X / N$, as are the boundary conditions. This second order differential equation will prove useful in parts of the analysis below.

The solid curve in Figure 3 depicts the qualitative features of an equilibrium matching function for given $a_{R}$. The least productive firms, with technology parameter $\varphi_{\min }$, employ the least able workers, with ability level $a_{\min }$. The most productive firms, with technology parameter $\varphi_{\max }$, employ the manufacturing sector's most able workers, with ability level $a_{R}$. Finally, the func-

${ }^{13}$ By (5), (6), and (7), a firm with productivity $\phi$ employs

$$
\ell(\phi)=\frac{X\left[\frac{\sigma}{\sigma-1} w[m(\phi)]\right]^{-\sigma}}{\psi[\phi, m(\phi)]^{1-\sigma}}
$$

workers. Therefore, the left-hand side of (12) gives the aggregate wage bill paid by all firms with technology parameter less than or equal to $\varphi$. The right-hand side of (12) is the aggregate wage income of workers with ability less than or equal to $m(\varphi)$

${ }^{14}$ For further discussion of uniqueness of this solution, see Appendix A2.4. 
Figure 3: Matching function

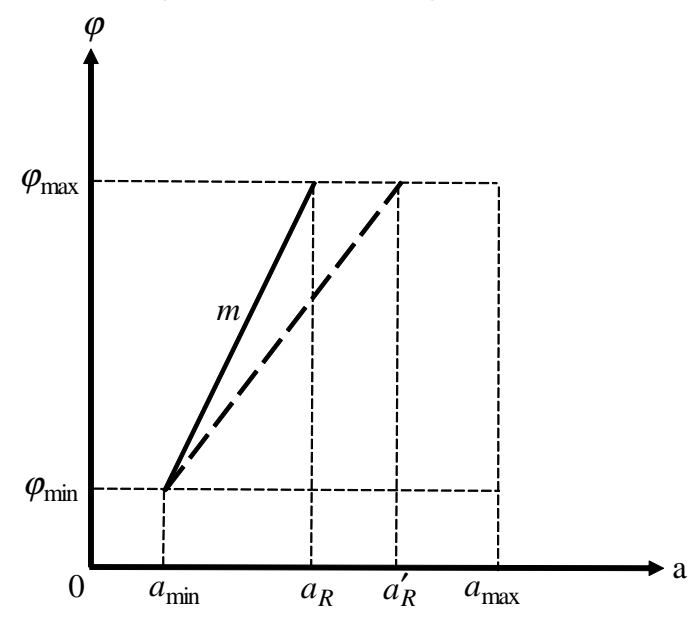

tion is continuous and monotonically increasing due to the complementarity between abilities and technologies. Now compare this matching function to one that emerges when the ability cutoff is higher, say $a_{R}^{\prime}>a_{R}$. The matching function $m\left(\varphi ; a_{R}^{\prime}\right)$ is depicted by the broken curve in the figure. In Grossman et al. (2013) we establish that the pair of solutions to (11) and (13) that apply for different boundary conditions can intersect at most once. ${ }^{15}$ But since the curves must intersect at the common lower boundary point, they cannot intersect again. It follows that when the manufacturing expands by an increase in $a_{R}$, every worker originally in the sector matches with a less productive firm than before, while every firm upgrades its workforce. This feature plays a key role in shaping wage inequality in manufacturing.

\subsection{The Balanced-Growth Path}

Equation (9) gives a relationship between the steady-state growth rate in the number of varieties and the set of resources allocated to R\&D. Now that we know that the workforce in research comprises all workers with ability above $a_{R}$ and only those workers. So, we can rewrite the equation as

$$
g_{M}=\theta_{K} N \int_{a_{R}}^{a_{\max }} T(a) d H(a) .
$$

The curve $R R$ in Figure 4 depicts this relationship between $g_{M}$ and $a_{R}$. The curve-which falls entirely in the positive quadrant - shows that faster growth in the number of varieties requires greater resources devoted to $\mathrm{R} \& \mathrm{D}$ and therefore a lower cutoff ability level for the marginal research worker.

We can derive a second long-run relationship between $g_{M}$ and $a_{R}$ using the labor-market clearing condition (12) and the long-run free entry condition, (10). First note that, given the ability cutoff $a_{R}$ and the matching function $m\left(\varphi ; a_{R}\right)$, the wage equation (11) in Lemma 1 allows us to compute

\footnotetext{
${ }^{15}$ For further discussion, see also Appendix A2.4.
} 
Figure 4: Equilibrum growth rate and ability cutoff

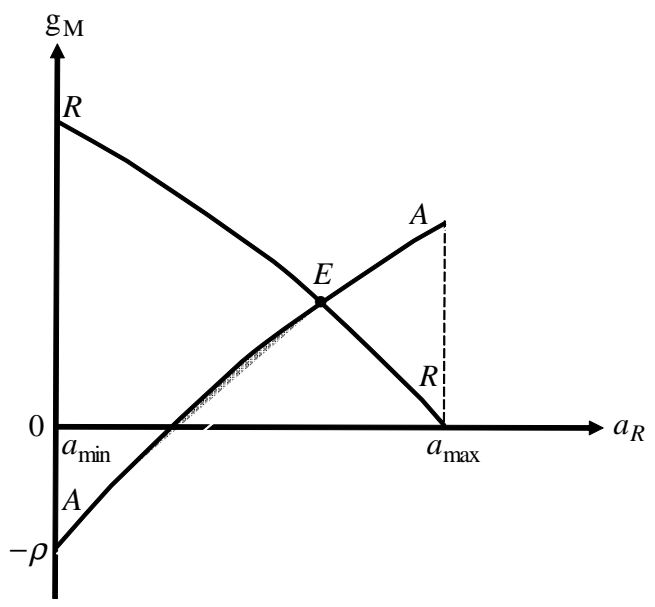

the wage of any worker in manufacturing relative to the wage of the least able worker. That is,

$$
\ln \lambda\left(a ; a_{R}\right)=\int_{a_{\min }}^{a} \frac{\psi_{a}\left[m^{-1}\left(v ; a_{R}\right), v\right]}{\psi\left[m^{-1}\left(v ; a_{R}\right), v\right]} d v \text { for all } a \in\left[a_{\min }, a_{R}\right],
$$

where $\lambda\left(a ; a_{R}\right) \equiv w(a) / w\left(a_{\min }\right)$. We emphasize, with the notation for $\lambda\left(a ; a_{R}\right)$, that this ratio depends only on $a_{R}$ and the parameters that affect the differential equation (15) for the matching function. Using (17), along with (10), (12) and the continuity of the wage function at $a_{R}$, we derive in Appendix A2.5 the following relationship between the long-run growth rate and the ability cutoff:

$$
\rho+g_{M}=\theta_{K} N \Lambda\left(a_{R}\right)
$$

where

$$
\Lambda\left(a_{R}\right) \equiv \frac{T\left(a_{R}\right)}{(\sigma-1) \lambda\left(a_{R} ; a_{R}\right)} \int_{a_{\min }}^{a_{R}} \lambda\left(a ; a_{R}\right) d H(a) .
$$

The $A A$ curve in Figure 4 illustrates this second relationship between $g_{M}$ and $a_{R}$. The fact that it is everywhere upward sloping also is established in the appendix.

The figure shows a unique balanced-growth equilibrium at point $E .{ }^{16}$ Once we know the longrun rate of growth in the number of intermediate goods, we can calculate the growth in consumption and wages from $g_{w}=g_{c}=g_{M} /(\sigma-1) .{ }^{17}$ Once we know the steady-state cutoff level of ability $a_{R}$, we can compute the long-run distribution of relative wages (and incomes) using the wage structures dictated by Lemmas 1 and 2 .

\footnotetext{
${ }^{16}$ If the $A A$ curve falls below the horizontal axis for all $a_{R} \leq a_{\max }$, then no workers are employed in the research sector in the steady state. In such circumstances, growth rates of varieties, final output, consumption and wages are all zero.

${ }^{17}$ Consumption grows in the long run at the rate of income, and wages are the sole source of income, because in the steady state the flow of operating profits just covers R\&D costs.
} 


\subsection{Measuring Inequality}

Before proceeding to analyze the determinants of long-run growth and income distribution in the closed economy, we conclude this section with a brief discussion about wage inequality and the size distribution of firms. We shall focus on measures of wage inequality such as the Theil index, the Atkinson index and Lorenz-curve dominance that are scale invariant (i.e., they are homogeneous of degree zero in all wages) and that respect second-order stochastic dominance. When comparing two wage distributions, we will say that one is strictly more unequal than the other if an appropriate proportional scaling of the former yields a distribution that is a mean-preserving spread of the latter. More formally, we first describe inequality among a limited range of workers with abilities in the interval $\left[a^{\prime}, a^{\prime \prime}\right] \subseteq\left[a_{\min ,} a_{\max }\right]$. We propose

Definition 1 Let $w(a)$ and $\tilde{w}(a)$ be continuous and increasing wage functions. The distribution of $w$ has strictly greater inequality than the distribution of $\tilde{w}$ on the interval $\left[a^{\prime}, a^{\prime \prime}\right]$ if there exists a scalar $\theta>0$ such that $\theta w(a) \neq \tilde{w}(a)$ for some $a \in\left[a^{\prime}, a^{\prime \prime}\right]$ and the conditional distribution of $\theta w$ is a mean-preserving spread of the conditional distribution of $\tilde{w}$.

If the wages $w(a)$ happen to be proportional to the wages $\tilde{w}(a)$ for all $a \in\left[a^{\prime}, a^{\prime \prime}\right]$, we will say that the two distributions have equal inequality in the interval.

Next, we turn to the full wage distribution. We rank inequality in two different distributions as follows.

Definition 2 Let $w(a)$ and $\tilde{w}(a)$ be continuous and increasing wage functions on $\left[a_{\min }, a_{\max }\right]$. The distribution of $w$ is everywhere more unequal than the distribution of $\tilde{w}$ if for every partition of $\left[a_{\min }, a_{\max }\right]$ the conditional distribution of $w$ has equal or strictly greater inequality than the conditional distribution of $\tilde{w}$ on every subinterval of this partition, and strictly greater inequality on at least one such subinterval.

To make comparisons of wage inequality both within and between countries, it will prove useful to rely on the single-crossing property of the mean-adjusted wage functions. That is, we shall apply

Lemma 4 Let $w(a)$ and $\tilde{w}(a)$ be continuous and increasing wage functions on $\left[a^{\prime}, a^{\prime \prime}\right]$ and choose $\theta$ such that the means of the conditional distributions of $\theta w$ and $\tilde{w}$ are the same. If there exists an $a^{*} \in\left(a^{\prime}, a^{\prime \prime}\right)$ such that $\theta w(a)<\tilde{w}(a)$ for all $a \in\left[a^{\prime}, a^{*}\right)$ and $\theta w(a)>\tilde{w}(a)$ for all $a \in\left(a^{*}, a^{\prime \prime}\right]$, then the conditional distribution of $w$ has strictly greater inequality than the conditional distribution of $\tilde{w}$.

The lemma follows immediately from the fact that the single-crossing property ensures that $\theta w(a)$ is a mean-preserving spread of $\tilde{w}(a)$. If we can establish a single-crossing property for mean-adjusted wage distributions, this suffices to allow a ranking of the distributions in terms of their inequality.

We show next how wage inequality within the manufacturing sector reflects the cutoff ability level, $a_{R}$. We have seen already in (17) that the ratio of the wage of any worker in the manufacturing 
Figure 5: Relative wages

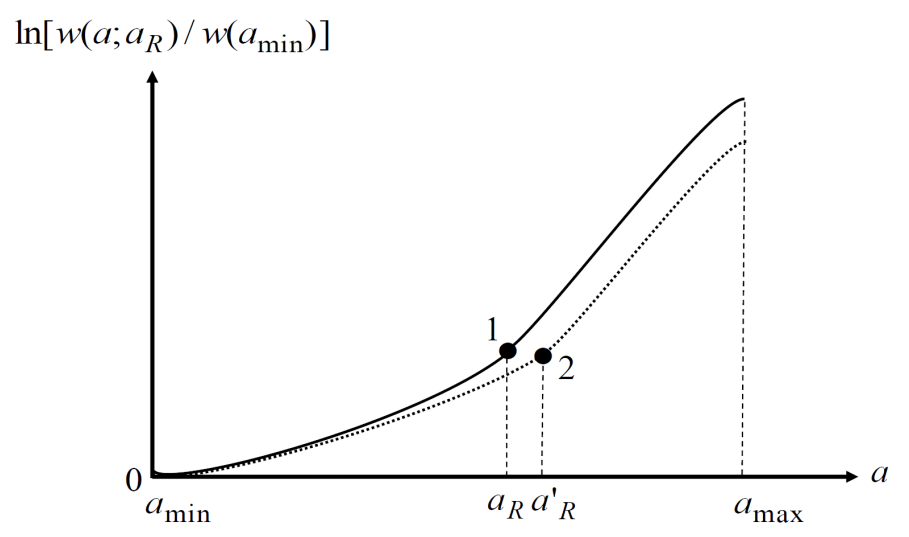

sector relative to that of the least-able worker is uniquely determined by $a_{R}$. Moreover, Figure 3 has been used to illustrate that an increase in $a_{R}$ causes all workers originally in manufacturing to match with less productive firms than before. The downgrade in technology harms the productivity of all of these workers, but - due to the complementarity between ability and technology - it especially harms those with relatively greater ability. In other words, we have ${ }^{18}$

Lemma 5 Suppose $a_{\max } \geq a_{R}^{\prime}>a_{R}>a_{\min }$. Then

$$
\frac{\lambda\left(a^{\prime \prime} ; a_{R}\right)}{\lambda\left(a^{\prime} ; a_{R}\right)}>\frac{\lambda\left(a^{\prime \prime} ; a_{R}^{\prime}\right)}{\lambda\left(a^{\prime} ; a_{R}^{\prime}\right)} \text { for all } a^{\prime \prime}>a^{\prime} \text { and } a^{\prime}, a^{\prime \prime} \in\left[a_{\min }, a_{R}\right] \text {. }
$$

Lemma 5 states that the relative-wage function $\lambda(\cdot)$ is log submodular in the ability of a worker and the ability cutoff level. Intuitively, relative wages behave like relative productivities, and since the cutoff level $a_{R}$ inversely affects the technology match for every worker, the function $\lambda\left(a, a_{R}\right)$ inherits the opposite properties as $\psi(a, \varphi)$. Note that since $\lambda\left(a_{\min }, a_{R}\right)=\lambda\left(a_{\min }, a_{R}^{\prime}\right)=1$, the lemma also implies that $\lambda\left(a, a_{R}\right)>\lambda\left(a, a_{R}^{\prime}\right)$ for all $a \in\left(a_{\min }, a_{R}\right)$. In words, an increase in the cutoff level shifts the relative-wage function for manufacturing downward.

The solid curve in Figure 5 depicts the relative wage structure (in logs) for an economy in which the cutoff ability level is $a_{R}$. To the left of $a_{R}, \ln \left[w(a) / w\left(a_{\min }\right)\right]=\ln \lambda\left(a ; a_{R}\right)$, where $\ln \lambda\left(a ; a_{R}\right)$ can be calculated using (17). The curve rises with slope $\psi_{a}\left[m^{-1}\left(a ; a_{R}\right), a\right] / \psi\left[m^{-1}\left(a ; a_{R}\right), a\right]$ in this range. To the right of $a_{R}, \ln \left[w(a) / w\left(a_{\min }\right)\right]=\ln \left[T(a) \lambda\left(a_{R} ; a_{R}\right) / T\left(a_{R}\right)\right]$, and the curve rises with slope $T^{\prime}(a) / T(a)$. By Assumption 2, the wage schedule becomes steeper at the cutoff point, labelled 1.

\footnotetext{
${ }^{18}$ By Assumption 1, a deterioration in the match for the worker with ability a reduces the expression under the integral in (17). It therefore reduces the relative wage of the worker with greater ability among any pair of workers in manufacturing.
} 
Now consider an increase in the cutoff point, to $a_{R}^{\prime}>a_{R}$. In Figure 5, the log of the new relative wage structure is depicted by the dotted curve. By Lemma 5 , the dotted curve must be flatter than the solid curve for all ability levels $a<a_{R}$. For $a>a_{R}^{\prime}$ the slopes of the two curves are the same, namely $T^{\prime}(a) / T(a)$. Finally, Assumptions 1 and 2 ensure that the dotted curve is flatter than the solid curve for all $a \in\left(a_{R}, a_{R}^{\prime}\right) .{ }^{19}$

These observations allow us to draw a number of conclusions about the relationship between the size of the manufacturing sector and wage inequality. First, when $a_{R}$ rises to $a_{R}^{\prime}$ (i.e., employment in manufacturing grows at the expense of $\mathrm{R} \& \mathrm{D}$ ), wage inequality falls among any range of workers $\left[a^{\prime}, a^{\prime \prime}\right] \subseteq\left[a_{\min }, a_{R}^{\prime}\right]$. This follows from Lemma 4 and the fact that the ex ante and ex post meanadjusted wage functions cross only once. Second, wage inequality remains the same after an increase in $a_{R}$ for every interval of workers $\left[a^{\prime}, a^{\prime \prime}\right] \subseteq\left[a_{R}^{\prime}, a_{\text {max }}\right]$. It follows, from Definition 2 that, other things equal, expansion of the manufacturing sector reduces wage inequality everywhere. More formally, we record

Lemma 6 Suppose $a_{R}, a_{R}^{\prime} \in\left[a_{\min }, a_{\max }\right]$, with $a_{R}^{\prime}>a_{R}$. Then the wage function $w\left(a ; a_{R}\right)$ is everywhere more unequal than the wage function $w\left(a ; a_{R}^{\prime}\right)$.

Finally, we note that the rematching of workers to firms that results from a change in the size and composition of the manufacturing sector has implications as well for the size distribution of firms. When the matches deteriorate for workers, as they do when the cutoff point for employment in manufacturing rises from $a_{R}$ to $a_{R}^{\prime}$ and the distribution of technologies $G(\varphi)$ remains the same, the matches improve for the firms that hire these workers. This rematching raises productivity for all firms, but especially so for those with more sophisticated technologies (as indexed by $\varphi$ ). Since the more productive firms gain the most in terms of either sales or revenues, the size distribution of firms widens. This gives us ${ }^{20}$

\footnotetext{
${ }^{19}$ Note that the slope of the solid curve in this range is $T^{\prime}(a) / T(a)$, whereas the slope of the dotted curve is $w^{\prime}\left(a ; a_{R}^{\prime}\right) / w\left(a ; a_{R}^{\prime}\right)=\lambda_{a}\left(a ; a_{R}^{\prime}\right) / \lambda\left(a ; a_{R}^{\prime}\right)=\psi_{a}\left[m^{-1}\left(a ; a_{R}^{\prime}\right), a\right] / \psi\left[m^{-1}\left(a ; a_{R}^{\prime}\right), a\right]$, by the definition of the relativewage function $\lambda(\cdot)$ and the wage equation (11). Assumption 2 implies

$$
\frac{\psi_{a}\left[m^{-1}\left(a ; a_{R}^{\prime}\right), a\right]}{\psi\left[m^{-1}\left(a ; a_{R}^{\prime}\right), a\right]}<\frac{T^{\prime}(a)}{T(a)} \text { for } a<a_{R}^{\prime} .
$$

${ }^{20} \mathrm{Using}$ the expression for $\ell(\varphi)$ from footnote 13 , the volume of output of a firm with technology $\varphi$ is

$$
x(\varphi)=\psi[\varphi, m(\varphi)] \ell(\varphi)=\frac{X\left[\frac{\sigma}{\sigma-1} w[m(\varphi)]\right]^{-\sigma}}{\psi[\varphi, m(\varphi)]^{-\sigma}},
$$
}

and, using (7), its revenue is

$$
r(\varphi)=p(\varphi) x(\varphi)=\frac{X\left[\frac{\sigma}{\sigma-1} w[m(\varphi)]\right]^{1-\sigma}}{\psi[\varphi, m(\varphi)]^{1-\sigma}}
$$

Equation (11) then implies that

$$
\ln x\left(\varphi_{2}\right)-\ln x\left(\varphi_{1}\right)=\sigma \int_{\varphi_{1}}^{\varphi_{2}} \frac{\psi_{\varphi}[\varphi, m(\varphi)]}{\psi[\varphi, m(\varphi)]} d \varphi \text { for all } \varphi_{1}, \varphi_{2} \in\left[\varphi_{\min }, \varphi_{\max }\right]
$$


Lemma 7 Suppose $a_{R}, a_{R}^{\prime} \in\left[a_{\min }, a_{\max }\right]$, with $a_{R}^{\prime}>a_{R}$. If the distribution of technologies $G(\varphi)$ is the same, then the size distribution of firm output and firm revenue is more unequal whenthe cutoff ability level is $a_{R}^{\prime}$ than when it is $a_{R}$.

Lemma 7 implies that, as long as the distribution of technologies does not change, changes in the size distribution of firms are opposite to changes in wage inequality among manufacturing workers. We will not record all of the implications for the firm size distribution below, but we note that they apply to all comparative statics except for those in Section 3.4 and 4.5.

\section{Growth and Inequality in Autarky Equilibrium}

In this section, we compare growth rates and inequality measures in a pair of closed economies. We consider countries $i$ and $j$ that are basically similar but differ in some technological or policy parameters. We focus on balanced-growth equilibria as described in Section 2. In the next section, we will perform similar cross-country comparisons for a set of open economies and examine how the opening of trade affects growth and inequality around the globe.

\subsection{Productivity in Manufacturing}

We begin by supposing that the countries differ only in their productivity in manufacturing, as captured by a Hicks-neutral technology parameter $\theta_{\psi}$. In country $c$, a unit of labor of type $a$ applied in a firm with technology $\varphi$ can produce $\psi_{c}(\varphi, a)=\theta_{\psi c} \psi(\varphi, a)$ units of a differentiated intermediate good. For the time being, the other characteristics of the countries are the same, including their sizes, their distributions of ability, their distributions of firm productivity, their discount rates and the efficiency of their knowledge accumulation.

In these circumstances, the matching function $m\left(\varphi ; a_{R}\right)$ that satisfies $(15)$ is common to both countries; i.e., a difference between $\theta_{\psi i}$ and $\theta_{\psi j}$ does not affect matching in the manufacturing sector for a given $a_{R}$. Therefore, the relative-wage function $\lambda\left(a ; a_{R}\right)$ also will be the same in both countries if they have the same cutoff point, as can be seen clearly from (17). But then the solution to (16) and (18) is the same for any values of $\theta_{\psi i}$ and $\theta_{\psi j}$. In other words, countries that differ only in the (Hicks-neutral) productivity of their manufacturing sectors share the same long-run growth rate and the same marginal worker in manufacturing. It follows that their wage distributionsas reflected by $w\left(a ; a_{R}\right) / w\left(a_{\min } ; a_{R}\right)$-are also the same for all $a \in\left[a_{\min }, a_{\max }\right]$. Hicks-neutral differences in manufacturing productivity do not generate long-run differences in autarky growth rates or income distribution, although they do affect income levels. We summarize in

Proposition 1 Suppose that countries $i$ and $j$ differ only in manufacturing labor productivity $\psi_{c}(\cdot)$ and that these differences are Hicks-neutral; i.e., $\psi_{c}(\cdot)=\theta_{\psi c} \psi(\cdot)$ for $c=i, j$. Then in autarky,

and

$$
\ln r\left(\varphi_{2}\right)-\ln r\left(\varphi_{1}\right)=(\sigma-1) \int_{\varphi_{1}}^{\varphi_{2}} \frac{\psi_{\varphi}[\varphi, m(\varphi)]}{\psi[\varphi, m(\varphi)]} d \varphi \text { for all } \varphi_{1}, \varphi_{2} \in\left[\varphi_{\min }, \varphi_{\max }\right]
$$

It follows from Assumption 1 that $\psi_{\varphi} / \psi$ rises when $m(\varphi)$ increases at all $\varphi$. 
both countries grow at the same rate in a balanced-growth equilibrium and both share the same structure of relative wages and the same degree of income inequality.

\subsection{Capacity to Innovate}

In our model, a country's capacity for innovation is described by three parameters: size, which determines the potential scale of the research activity; the productivity of research workers of a given ability level; and the efficiency with which research experience is converted into knowledge capital. In this section, we compare autarky growth rates and income distributions in countries that differ in labor force, $N_{c}$, in efficiency of knowledge accumulation, $\theta_{K c}$, and in the productivity of research workers, as captured by a Hicks-neutral shift parameter $\theta_{T c}$, where $T_{c}(a)=\theta_{T c} T(a)$.

The $R R$ curve in Figure 4 is described by equation (16). In this equation, the aforementioned parameters enter as a product; i.e., the right-hand side of the equation is proportional to $\theta_{K c} N_{c} \theta_{T c}$, for given $a_{R}$ and a common $T(a)$ schedule. The same product also enters into equation (18) for the $A A$ curve. Here, the relative-wage function $\lambda\left(a ; a_{R}\right)$ appears under the integral. However, none of the three parameters under consideration enters into the second-order differential equation (15) that determines the the matching function for given $a_{R}$, and therefore none affects the relative wage function $\lambda\left(a ; a_{R}\right)$ for given $a_{R}$. It follows that the right-hand side of (18) also is proportional to $\theta_{K c} N_{c} \theta_{T c}$, for given $a_{R}$. In turn, this implies that $\theta_{K c} N_{c} \theta_{T c}$ is a sufficient statistic for the innovation capacity in country $c$; variation in this product explains cross-country variation in (autarky) longrun growth rates and income distribution, all else the same.

Now consider two countries $i$ and $j$ that differ in innovation capacity such that $\theta_{K i} N_{i} \theta_{T i}>$ $\theta_{K j} N_{j} \theta_{T j}$. Under these circumstances, the $A A$ and $R R$ curves for country $i$ lie above those for country $j$. But relative to the equilibrium cutoff point $a_{R j}$ in country $j$, the $A A$ curve in country $i$ passes above the $R R$ curve in that country. ${ }^{21}$ It follows that the equilibrium point for country $i$ lies above and to the left of that for country $j$; i.e., country $i$ devotes more resources to R\&D and grows faster in the long run.

What are the implications for the comparison of the two wage distributions? By Lemma 6, we know that wages are more equally distributed in country $j$, where the range of ability levels allocated to manufacturing is larger. The faster growing country has a greater share of workers in $\mathrm{R} \& \mathrm{D}$ and thus a less able set of workers in its manufacturing sector compared to the slower growing country. As a result, each manufacturing worker in country $i$ is paired with a better technology than his counterpart of similar ability in country $j$. This favors especially the more able manufacturing workers in country $i$, due to the complementarity between ability and technology. It follows that for any two ability levels employed in manufacturing in both countries, the relative wage of the more able in the pair is higher in country $i$ than in country $j$. The allocation of a greater share of workers to research in country $i$ compared to country $j$ further contributes to its greater wage inequality, inasmuch as wages rise more rapidly with ability in the $R \& D$ sector than they do in

\footnotetext{
${ }^{21}$ An increase in $\theta_{K} N \theta_{T}$ shifts the $R R$ curve up proportionately, but it shfits the $A A$ curve up more than propoportionately.
} 
manufacturing.

We summarize these findings in

Proposition 2 Suppose that countries $i$ and $j$ differ only in their capacity for innovation and that $\theta_{K i} N_{i} \theta_{T i}>\theta_{K j} N_{j} \theta_{T j}$. Then, in autarky, country $i$ grows faster in a balanced-growth equilibrium than country $j$ and it has everywhere a more unequal wage distribution.

Note that a country with a large population may have a low capacity for innovation, if its workers are not very productive in the research sector or if (for institutional or other reasons) it does not convert research experience into knowledge capital very efficiently. But whatever the source of a country's innovation capacity, the larger is its capacity to conduct R\&D the faster will be its long-run growth in autarky and the more unequal will be its distribution of earnings.

\subsection{Support for R\&D}

Next we examine the role that research policy plays in shaping growth and inequality, focusing specifically on cross-country differences in R\&D subsidies. We consider symmetric countries $i$ and $j$ that differ only in their subsidy rates, $s_{i}$ and $s_{j}$. In each country, the subsidy is financed by a proportional tax on wages. ${ }^{22}$ With a subsidy in place, a research firm in country $c$ pays a cost $\left(1-s_{c}\right) w_{c}(a) / T(a) \theta_{K} M_{c}$ to invent a new variety when it hires researchers with ability $a$. Accordingly, the free-entry condition that gives rise to the $A A$ curve in Figure 4 is replaced by

$$
\left(1-s_{c}\right)\left(\rho+g_{M c}\right)=\theta_{K} N \Lambda\left(a_{R c}\right) \text {. }
$$

Neither equation (16) that relates growth to resources invested in $\mathrm{R} \& \mathrm{D}$, nor the $R R$ curve that depicts this relationship, is affected by the subsidy.

It follows immediately that, if $s_{i}>s_{j}$, the $A A$ curve for country $i$ rests above and to the left of that for country $j$. Not surprisingly, the subsidy draws labor into the research sector and, thereby, stimulates growth. The link to the income distribution should also be clear by now. With $a_{R i}<a_{R j}$, the technology matches are better for manufacturing workers of a given ability in country $i$ than in country $j$, which generates a more unequal distribution of wages. The larger size of the research sector in country $i$ also contributes to its greater inequality, because ability is more amply rewarded in $R \& D$ than in manufacturing. In short, the country with the larger R\&D subsidy experiences greater wage inequality.

Proposition 3 Suppose that countries $i$ and $j$ differ only in their RED subsidies and that $s_{i}>s_{j}$. Then, in autarky, country $i$ grows faster in a balanced-growth equilibrium than country $j$ and it has everywhere a more unequal wage distribution.

\footnotetext{
${ }^{22}$ Such a proportional levy leaves the after-tax distribution of income the same as the pre-tax distribution and, because labor is supplied inelastically, it has no effect on resource allocation.
} 
Figure 6: Matching for different values of $\bar{\varphi}_{c}$

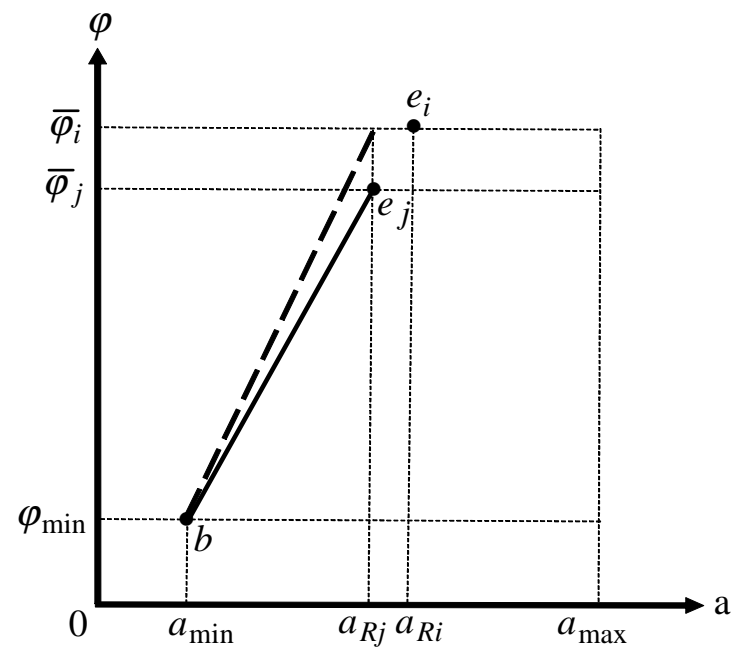

In Section 4.4, we will revisit the effects of $R \& D$ subsidies for an open economy and will address the spillover effects of such subsidies on growth and inequality in a country's trading partners. We will see that R\&D subsidies increase inequality not only at home, but ubiquitously around the globe.

\subsection{Manufacturing Technologies}

Recall that an inventor draws a technology $\varphi$ from a set of possible technologies for producing intermediate goods according to the distribution function $G(\cdot)$. Countries may differ in the set of technologies that their inventors can access. To explore how such differences affect growth and inequality, we take $G_{c}(\varphi)$ to be a truncated Pareto distribution with domain $\left[\varphi_{\min }, \bar{\varphi}_{c}\right]$ for $c=i, j$ and $\bar{\varphi}_{i}>\bar{\varphi}_{j}$. The countries otherwise are alike including in the "shapes" of their technology distributions. $^{23}$

Specifically, let

$$
G_{c}(\varphi)=\frac{\varphi_{\min }^{-k}-\varphi^{-k}}{\varphi_{\min }^{-k}-\bar{\varphi}_{c}^{-k}} \text { for all } \varphi \in\left[\varphi_{\min }, \bar{\varphi}_{c}\right], c=i, j, k>2
$$

Here, $k$ is the shape parameter, common to the two countries. With this formulation, the technological possibilities facing inventors in country $i$ first-order stochastically dominate those facing inventors in country $j .{ }^{24}$

Note that $G_{c}^{\prime \prime}(\varphi) / G_{c}^{\prime}(\varphi)$ is independent of $c$ in the overlapping range of $\varphi$. The other terms in the second-order differential equation (15) for the matching function in country $c$ are common in

\footnotetext{
${ }^{23}$ We adopt a truncated Pareto distribution to parmaterize $G(\cdot)$, because there are no sharp results for arbitrary differences in the technology sets, even if the draws in one country first-order stochastically dominate those in the other.

${ }^{24}$ We could also allow for cross-country differences in the lower bound of the productivity distribution, $\varphi_{\min }$. As long as the ordering of the lower bounds is the same as that of the upper bounds, our results would be the same. We assume a common lower bound in order to simplify the exposition.
} 
the two countries as well. It follows that differences in matching between workers and technologies arise only because the boundary conditions (14) are different in the two countries, and not because the solutions for the matching functions take different forms. ${ }^{25}$ To emphasize this point, we write the matching function for country $c$ as $m\left(\varphi ; a_{R c}, \bar{\varphi}_{c}\right)$ for $c=i, j$.

The inverse-matching functions for the two countries commence at the same point $\left(a_{\min }, \varphi_{\min }\right)$, as depicted in Figure 6. Since they can intersect only once, the (dotted) curve for country $i$ would need to lie to the left of the (solid) curve for country $j$ if the ranges of ability levels allocated to manufacturing in the two countries happened to be the same. In other words, $m\left(\varphi ; a_{R}, \bar{\varphi}_{i}\right)<$ $m\left(\varphi ; a_{R}, \bar{\varphi}_{j}\right)$ for all $\varphi \in\left(\varphi_{\min }, \bar{\varphi}_{j}\right]$. This means that a worker of given ability would find a better technology match in country $i$ than in country $j$ if the ability of the marginal worker were the same, thanks to the fact that country $i$ makes use of a strictly superior mix of technologies. In turn, this implies that $\lambda\left(a ; a_{R}, \bar{\varphi}_{i}\right)>\lambda\left(a ; a_{R}, \bar{\varphi}_{j}\right)$ for all $a \in\left(a_{\text {min }}, a_{R}\right]$; the complementarity between ability and technology would give rise to a higher relative wage for a worker of any ability $a>a_{\text {min }}$ (compared to the wage of the least able worker) in the country with the better technology draws. For a similar reason, the relative wage of a worker of any ability $a<a_{R}$ compared to the wage of the worker with ability $a_{R}$ would be lower in country $i$ than in country $j$ if the cutoff ability levels were the same; i.e., $\lambda\left(a ; a_{R}, \bar{\varphi}_{i}\right) / \lambda\left(a_{R} ; a_{R}, \bar{\varphi}_{i}\right)>\lambda\left(a ; a_{R}, \bar{\varphi}_{j}\right) /\left(a_{R} ; a_{R}, \bar{\varphi}_{j}\right)$.

This last observation implies that the $A A$ curve for country $i$ lies below that for country $j$. To see this, note the equation for the $A A$ curve (18) and the fact that

$$
\Lambda\left(a_{R} ; \bar{\varphi}_{c}\right) \equiv \frac{T\left(a_{R}\right)}{(\sigma-1)} \int_{a_{\min }}^{a_{R}} \frac{\lambda\left(a ; a_{R}, \bar{\varphi}_{c}\right)}{\lambda\left(a_{R} ; a_{R}, \bar{\varphi}_{c}\right)} d H(a)
$$

It follows that $\Lambda\left(a_{R} ; \bar{\varphi}_{i}\right)<\Lambda\left(a_{R} ; \bar{\varphi}_{j}\right)$. However, the $R R$ curve is the same in the two countries inasmuch as the production technology set does not affect the relationship between the labor allocated to R\&D and the resulting growth rate of the number of varieties. We conclude that $g_{M i}<g_{M j}$ and that $a_{R i}>a_{R j}$. Intuitively, we find that among two countries that are otherwise similar, the one that draws from a better set of technologies for producing intermediate goods devotes more resources to manufacturing and less to innovation.

Now we are ready to compare the equilibrium wage distributions in the two countries. There are two offsetting forces. On the one hand, the superior mix of technologies alone would make the matches for manufacturing workers in country $i$ better than those for their counterparts in country $j$, if the same set of worker types happened to sort into manufacturing in the two countries. On the other hand, we have just seen that a wider range of workers sorts into manufacturing in country $i$ than in country $j$, and since the marginal workers in the sector are better than the average, a worker of a given ability level finds it more difficult to match with a good firm due to the greater competition in the labor market. The apparent ambiguity can be seen in Figure 6; depending on the distance between $a_{R i}$ and $a_{R j}$, it appears that the inverse-matching curve for country $i$, which

\footnotetext{
${ }^{25}$ In other words, in the solution to the differential equations (11) and (13) for given boundary conditions, the value of $\bar{\varphi}_{c}$ impacts the level of wages, but not the resulting matches between worker types and technologies.
} 
Figure 7: Relative wages in countries $i$ and $j$, when $\bar{\varphi}_{i}>\bar{\varphi}_{j}$

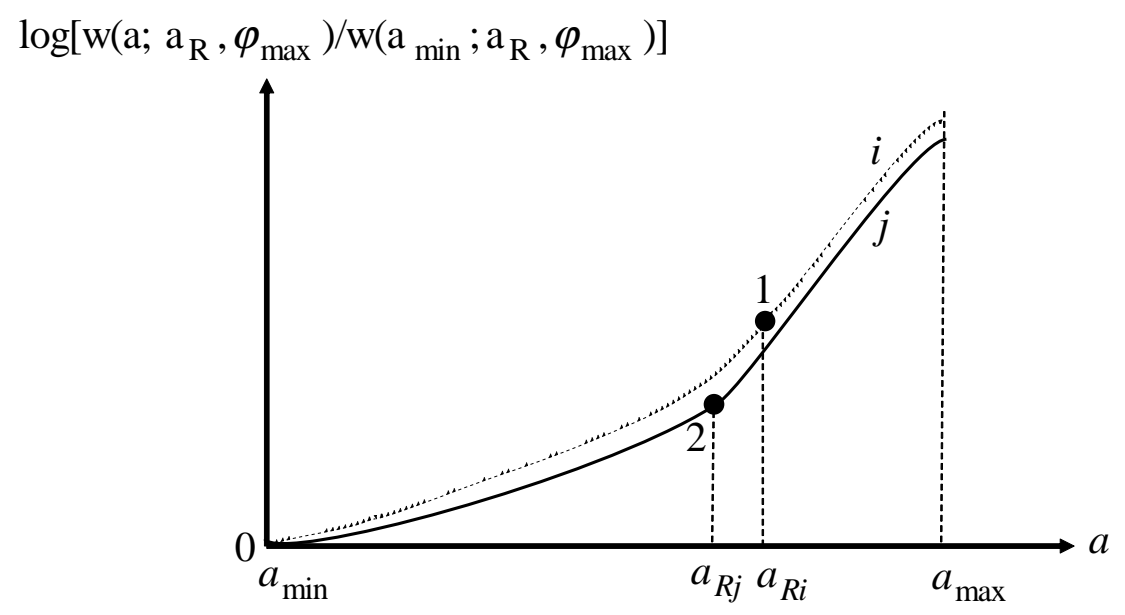

extends from $\left(a_{\min }, \varphi_{\min }\right)$ to a point such as $e_{i}$, could lie above or below that for country $j$, which extends from the same starting point to point $e_{j}$.

The ambiguity is only apparent, however. We find that the better matching that is associated with a superior technology set can never be fully (or more than fully) offset by the endogenous response of the composition of workers in the sector. ${ }^{26}$ In other words, the inverse-matching function for country $i$ must lie above the inverse-matching function for country $j$, even after the difference between $a_{R i}$ and $a_{R j}$ has been taken into account. In the new equilibrium, all worker types $a \in$ $\left(a_{\text {min }}, a_{R j}\right]$ find better technology matches in country $i$ than in country $j$. This generates strictly greater wage inequality among workers with abilities in this range.

Figure 7 depicts (log) relative wages in the two countries, including workers employed in both the manufacturing and research sectors. For $a>a_{R i}$, the two curves have the same slopes, because wages of research workers rise at the same rate in both countries as a reflection of their common research productivities. For $a<a_{R j}$, relative wages rise faster with ability in country $i$ than in country $j$, because workers there achieve better technological matches than their counterparts and productivity in manufacturing is log supermodular in technology and ability. Finally, for $a \in$ $\left(a_{R j}, a_{R i}\right)$, wages rise more rapidly with ability in country $j$ than in country $i$, because these ability levels are allocated to $\mathrm{R} \& \mathrm{D}$ in $j$, but to manufacturing in $i$, and by Assumption 2, productivity is

${ }^{26}$ Inasmuch as $g_{M i}<g_{M j}$,

$$
\rho+g_{M i}<\rho+g_{M j}=\theta_{K} N \Lambda\left(a_{R j} ; \bar{\varphi}_{j}\right)=\frac{\theta_{K} N T\left(a_{R j}\right)}{(\sigma-1) \lambda\left(a_{R j} ; a_{R j}, \bar{\varphi}_{j}\right)} \int_{a_{\min }}^{a_{R j}} \lambda\left(a ; a_{R j}, \bar{\varphi}_{j}\right) d H(a) .
$$

Now suppose it were the case that $m\left(\varphi ; a_{R j}, \bar{\varphi}_{j}\right)<m\left(\varphi ; a_{R i}, \bar{\varphi}_{i}\right)$ for all $\varphi \in\left(\varphi_{\min }, \bar{\varphi}_{j}\right]$. Then $\lambda\left(a ; a_{R j}, \bar{\varphi}_{j}\right) / \lambda\left(a_{R j} ; a_{R j}, \bar{\varphi}_{j}\right)<\lambda\left(a ; a_{R i}, \bar{\varphi}_{i}\right) / \lambda\left(a_{R j} ; a_{R i}, \bar{\varphi}_{i}\right)$ for all $a \in\left(a_{\min }, a_{R j}\right]$, which would imply that

$$
\rho+g_{M i}<\rho+g_{M j}=\theta_{K} N \Lambda\left(a_{R j}, \bar{\varphi}_{j}\right)<\frac{\theta_{K} N T\left(a_{R j}\right)}{(\sigma-1) \lambda\left(a_{R j} ; a_{R i}, \bar{\varphi}_{i}\right)} \int_{a_{\min }}^{a_{R j}} \lambda\left(a ; a_{R i}, \bar{\varphi}_{i}\right) d H(a) .
$$

The expression on the far right-hand side of this inequality chain is rising in $a_{R j}$ by Lemma 2 , and thus it implies $\rho+g_{M i}<\theta_{K} N \Lambda\left(a_{R i}, \bar{\varphi}_{i}\right)$. But this contradicts condition (18) for country $i$. 
more responsive to ability in research than in manufacturing.

What then can we say about the comparison of income distributions in the two countries? Our analysis suggests that the wage distribution is strictly more unequal in the country with the better manufacturing technologies at the bottom end of the wage distribution, but that the opposite is true at the top end of the distribution. For the entire earnings structure, the two wage distributions cannot be unambiguously ranked. We collect our findings in

Proposition 4 Suppose that countries $i$ and $j$ differ only in their distributions of manufacturing technologies, that $G_{c}(\varphi)$ is a truncated Pareto distribution with shape $k$ and range $\left[\varphi_{\min }, \bar{\varphi}_{c}\right]$ in country $c$, and that $\bar{\varphi}_{i}>\bar{\varphi}_{j}$. Then, in autarky: (i) $g_{M i}<g_{M j}$; (ii) the wage distribution is strictly more unequal in $i$ than in $j$ for any interval $\left[a^{\prime}, a^{\prime \prime}\right] \subseteq\left[a_{\min }, a_{R j}\right]$; (iii) the wage distribution is weakly more unequal in $j$ than in $i$ for any interval $\left[a^{\prime}, a^{\prime \prime}\right] \subseteq\left[a_{R j}, a_{\max }\right]$; (iv) there exists an intermediate range of abilities $\left[a^{*}, a^{* *}\right] \subseteq\left[a_{R j}, a_{R i}\right]$ such that for $a \in\left[a^{*}, a^{* *}\right], w_{i}(a) / w_{i}\left(a_{\min }\right)>$ $w_{j}(a) / w_{j}\left(a_{\min }\right)$ and $w_{i}(a) / w_{i}\left(a_{\max }\right)>w_{j}(a) / w_{j}\left(a_{\max }\right)$.

Proposition 4 raises two interesting possibilities. First, the cross-country correlation between growth rates and measures of income inequality need not be positive. Cross-country differences in innovation capacity or in $R \& D$ subsidies do generally indicate such a positive correlation in our model, but the correlations that arise when countries differ in their technology draws can go either way and presumably will depend upon the exact measure of inequality inasmuch as the various measures weigh differently the different segments of the wage distribution. Second, the cross-country results can also be interpreted in terms of comparative statics for a single country. With this interpretation, an increase in $\bar{\varphi}$ induces a growth slowdown together with an increase in the relative wages of middle-ability workers compared to those at either extreme.

\section{Growth and Inequality in a Trading Equilibrium}

In this section, we introduce international trade among a set of countries that differ in size, in research productivity, in manufacturing technologies, in capacity to create and absorb international knowledge spillovers, and in their innovation and trade policies. First, we examine the effects of trade on growth and income inequality in a typical country. Then, we allow countries to differ along one dimension at a time and ask how each difference is reflected in the cross-country comparison of their income distributions. We also explore the spillover effects of policies and parameters in one country on growth and income inequality in its trading partners.

Our trading environment has $C$ countries indexed by $c=1, \ldots, C$. In country $c$, there are $N_{c}$ workers with a distribution of abilities, $H(a) \cdot{ }^{27}$ A worker with ability $a$ who applies a technology

\footnotetext{
${ }^{27} \mathrm{By}$ assuming that the distribution of worker types is common to the countries, we neglect how differences in factor composition such as those emphasized in Grossman and Helpman (1991, ch.7) interact with factor intensities to influence the effects of trade on a country's long-run growth. Note too that we have only one manufacturing sector and one primary factor of production (albeit, a heterogeneous factor), whereas Grossman and Helpman (1991) typically studied economies with two primary factors and two sectors that differ in factor intensity. See Grossman et
} 
$\varphi$ in country $c$ can produce $\theta_{\psi c} \psi(\varphi, a)$ units of any intermediate good, where $\psi(\varphi, a)$ again has the complementarity properties described by Assumption 1 and $\theta_{\psi c}$ is, as before, a parameter that allows for Hicks-neutral productivity differences in the manufacturing sector across countries. In the research sector, a worker with ability $a$ has potential productivity $\theta_{T c} T(a) K_{c}$, where $\theta_{T c}$ reflects the research productivity of workers of a given type in country $c$ and $K_{c}$ is the national stock of knowledge capital, about which we will have more to say in a moment.

To ease the exposition, we will assume except in Section 4.5 that inventors in all countries draw manufacturing technologies from a common distribution $G(\varphi)$. Note, however, that Proposition 5 below that compares the growth rate and income inequality in a trade equilibrium to those in a country's autarky equilibrium would apply as well to a trading environment in which inventors worldwide face truncated Pareto distributions of possible technology outcomes with a common shape parameter, but with different bounds in each country.

We suppose that the government in country $c$ subsidizes the invention of new varieties of intermediate goods at rate $s_{c}$. All existing varieties of such goods are internationally tradable subject to trading frictions. We model these frictions as a combination of iceberg trading costs and ad valorem tariffs, so that the delivered price of any intermediate good imported from country $j$ and delivered in country $c$ is $\tau_{j c}$ times as great as the price received by the exporter in the source country. The budget deficit (or surplus) generated by the $\mathrm{R} \& \mathrm{D}$ subsidies net of tariff revenue is financed (or redistributed) by a proportional tax (or subsidy) on wages.

Final goods are assumed to be nontradable. ${ }^{28}$ Let $q_{c}$ represent the price of the final good in country $c, p_{j c}(\omega)$ the price there of variety $\omega$ of an intermediate good imported from country $j$, and $\Omega_{j}$ the set of intermediate goods produced in country $j$. Competitive pricing of final goods implies that

$$
\left\{\sum_{j=1}^{C}\left[\int_{\omega \in \Omega_{j}} p_{j c}(\omega)^{1-\sigma} d \omega\right]\right\}^{\frac{1}{1-\sigma}}=q_{c},
$$

while the choice of numeraire allows us to set any one of these prices equal to one. We denote by $X_{c}$ the output of final goods in country $c$.

We describe now the differences in national knowledge stocks and in countries' abilities to apply knowledge capital in the R\&D process. As is well known from the literature on endogenous growth in the open economy (see, for example, Grossman and Helpman, 1991), the extent of international knowledge spillover plays an important role in determining the effects of trade on long-run growth. The evidence surveyed by Helpman (2004, ch.5) points to the existence of significant but incomplete international R\&D spillovers. Coe et al. (2009) find, for example, that a country's researchers benefit differentially from domestic and foreign $R \& D$ experience and that the capacity to absorb

al. (2013) for a static analysis of the interplay between factor heterogeneity and sectoral factor intensities in shaping factor rewards.

${ }^{28}$ Our results concerning the effects of trade on growth and inequality and the spillover effects of policy would also apply if the final good were freely traded. However, in such circumstances, the final good would only be produced in the country (or countries) with the minimum cost of producing these goods as determined by aggregating the domestic prices of the various domestic and imported intermediates. 
domestic and foreign knowledge depends on a country's institutions and in particular on its regime for protection of intellectual property rights and the quality of its tertiary education. To capture this reality, we assume that the stock of knowledge in country $c$ is given by

$$
K_{c}=\sum_{j=1}^{C} \theta_{K j c} M_{j},
$$

where $\theta_{K j c}$ is a parameter that reflects the extent to which cumulative research experience in country $j$ contributes to inventors' productivity in country $c$. We assume that $\theta_{K j c}>0$ for all $j$ and $c$, so that every country reaps some spillover benefits from research that takes place anywhere in the world. Note that $\theta_{K c c}$ measures the effectiveness with which country $c$ converts its own research experience into usable knowledge; this parameter is the same as what we denoted by $\theta_{K}$ in Section 2.3 above. The special case of complete international spillovers into country $c$ can be represented by setting $\theta_{K j c}=\theta_{K c}$ for all $j$. If spillovers are complete and countries are symmetric in their abilities to absorb knowledge, then $\theta_{K j c}=\theta_{K}$ for all $j$ and $c$.

\subsection{The Effects of Trade on Growth and Inequality}

To solve the open-economy model, we make use of a separability property of the dynamic equilibrium. First note that, along a balanced-growth path, the number of differentiated varieties grows at the same rate in all countries; i.e., $\dot{M}_{c} / M_{c} \equiv g_{M c}=g_{M}$ for all $c$. In our one-sector model, this implies a convergence also in growth rates of per capita income. ${ }^{29}$ The output of final goods, $X$, in the equations for the profits of a typical intermediate good (8) and in the labor-market clearing condition (12), is replaced in the open economy by the market access $\bar{X}_{c}$ facing a typical producer of intermediates in country $c$, where

$$
\bar{X}_{c}=\sum_{j} \tau_{j c}^{1-\sigma} q_{j}^{\sigma} X_{j}
$$

This variable, as defined by Redding and Venables (2004), scales the aggregate demand facing an intermediate good producer in country $c$ (given its price), considering the production of final goods in each market, the cost of overcoming the trade barrier specific to the market, and the competition the firm faces from other intermediate goods sold in that market (as reflected in the price index for intermediate goods). Since this variable enters multiplicatively on the left-hand side of (12), the form of the matching function as described by the second-order differential equation (15) remains the same for the open economy as for the closed economy.

We can solve for the growth rate of varieties in country $c$ and the cutoff point for labor allocation

\footnotetext{
${ }^{29}$ As we know from Grossman and Helpman (1991), growth rates of per capita income can vary across countries if there are multiple industries that produce final goods and if countries differ in the compositions of their long-run production patterns.
} 
$a_{R c}$ using two equations analogous to (16) and (18). In place of the former, we have

$$
g_{M c}=g_{M}=\kappa_{c} N_{c} \theta_{T c} \int_{a_{R c}}^{a_{\max }} T(a) d H(a)
$$

where $\kappa_{c} \equiv K_{c} / M_{c}$ is the ratio of the knowledge stock in country $c$ to the country's own cumulative experience in research. In place of the latter (and taking into account the R\&D subsidy), we have

$$
\left(1-s_{c}\right)\left(\rho+g_{M c}\right)=\kappa_{c} N_{c} \theta_{T c} \Lambda\left(a_{R c}\right)
$$

where

$$
\Lambda\left(a_{R c}\right) \equiv \frac{T\left(a_{R c}\right)}{(\sigma-1) \lambda\left(a_{R c} ; a_{R c}\right)} \int_{a_{\min }}^{a_{R c}} \lambda\left(a ; a_{R c}\right) d H(a)
$$

and $\lambda\left(a ; a_{R c}\right)$ is determined by an equation just like (17). The solution to (20) and (21) gives the long-run values of $g_{M c}$ and $a_{R c}$ and the latter determines the entire distribution of relative wages in country $c$, using (17) and Lemma 2. Then, separately, we can use a set of trade balance conditions and labor-market clearing conditions to solve for the relative prices of final goods and the wage levels in each country.

A key observation is that $\kappa_{c}>\theta_{K c c}$ for all $c$. That is, in an open economy, researchers anywhere can draw on not only their own country's accumulated research experience when inventing new products, but also to some extent on the research experience that has accumulated outside their borders. No matter what the extent of international knowledge spillovers, so long as they are positive, a research firm in any country can be more productive in the open economy than in autarky. This greater productivity translates a given labor input into greater innovation by (20) and it reduces the cost of $R \& D$ that is embedded in the zero-profit condition in (21).

Now we are ready to compare (20) and (21) to their analogs that describe the closed-economy equilibrium (with R\&D subsidies). Note that the bigger $\kappa_{c}$ appears in place of the smaller $\theta_{K c c}$ (i.e., $\left.\theta_{K}\right)$ in each equation. Thus, the $R R$ curve for the open economy lies proportionately above that for the closed economy, whereas the $A A$ curve for the open economy lies more than proportionately above that for the closed economy. The two curves that determine the open-economy equilibrium in country $c$ cross above and to the left of the intersection depicted in Figure 4. Thus, in a trade equilibrium, every country devotes more labor to research than in autarky and it invents new varieties at a greater rate. The expansion of the research sector (fall in $a_{R c}$ ) generates an increase in wage inequality, both as a reflection of the re-matching of the given mix of technologies with a smaller and less able set of manufacturing workers and of the greater number of workers in research, where ability is more amply rewarded. Meanwhile, the acceleration of innovation generates faster growth of wages and final output. We have established

Proposition 5 Suppose that intermediate goods are tradable. Countries may differ in their manufacturing productivities, their research productivities, their labor supplies, their RESD subsidies, and their import tariffs. In a balanced-growth equilibrium, every country grows faster with trade than in autarky and every country has everywhere a more unequal income distribution with trade than 
in autarky.

\subsection{Differences in Manufacturing Productivity and Trade Barriers}

Suppose now that countries differ only in their manufacturing productivities, as parameterized by $\theta_{\psi c}$, and in their trade barriers, as reflected in $\tau_{j c}$. For the moment, we assume they are equal in size $\left(N_{c}=N\right.$ for all $\left.c\right)$, equal in research productivity $\left(\theta_{T c}=\theta_{T}\right.$ for all $\left.c\right)$, have similar R\&D subsidies $\left(s_{c}=s\right.$ for all $c$ ) and benefit symmetrically from complete international knowledge spillovers $\left(\theta_{K j c}=\theta_{K}\right.$ for all $j$ and $\left.c\right)$. In these circumstances, a balanced-growth path with $g_{M c}=g_{M}$ requires $\kappa_{c}=\kappa$ and $a_{R c}=a_{R}$ for all $c$, per equations (20) and (21). It follows that not only do the long-run growth rates converge internationally, but so too do the sizes and compositions of the research sectors. Then, matching between technologies and worker types is the same in all countries, and (17) applies worldwide with the same value of $a_{R}$. As a result, the relative-wage structure in the manufacturing sector is the same in all countries. So too is the wage profile in $\mathrm{R} \& \mathrm{D}$, by Lemma 2. In short, the same wage profile emerges in all countries, up to a factor of proportionality. The differences in manufacturing productivity and import tariff rates generate cross-country heterogeneity only in wage levels. We summarize in

Proposition 6 Suppose that intermediate goods are tradable and countries differ only in manufacturing productivities and import tariffs. Then all countries grow at the same rate in a balancedgrowth equilibrium and all have the same wage inequality in the long run.

It is also clear that, in these circumstances, the long-run value of $\kappa$ is independent of any $\theta_{\psi c}$ and $\tau_{j c}$, in which case (20) and (21) imply that changes in manufacturing productivities or in trade frictions do not affect the long-run growth rate or relative wages in any country. ${ }^{30}$ Moreover, $\kappa_{c}$ would be independent of $\theta_{\psi c}$ and $\tau_{j c}$ (albeit not necessarily common across countries) if countries were of different sizes, had different R\&D subsidies, had different research productivities, or had different capacities to generate or absorb international R\&D spillovers. The parameters $\theta_{\psi c}$ and $\tau_{j c}$ do, of course, affect income levels and consumer welfare.

\subsection{Differences in Innovation Capacity and in Ability to Create and Absorb Knowledge Spillovers}

Now suppose that all countries have equal $\mathrm{R} \& \mathrm{D}$ subsidy rates $\left(s_{c}=s\right.$ for all $\left.c\right)$. They may differ in size $\left(N_{c}\right)$ and in research productivity $\left(\theta_{T c}\right)$. Moreover, there may be differences in their abilities to absorb R\&D spillovers from abroad and in their abilities to convert research experience (their own and foreign) into usable knowledge that facilitates subsequent innovation. Such differences are reflected in the arbitrary matrix $\Theta_{K}=\left\{\theta_{K j c}\right\}$ of spillover parameters that determines knowledge

\footnotetext{
${ }^{30}$ With $\theta_{K j c}=\theta_{K}$ for all $j$ and $c$, (19) yields $K_{c}=\theta_{K} \sum_{j=1}^{C} M_{j}$ for all $c$, and thus $\kappa_{c}=\theta_{K}\left(\sum_{j=1}^{C} M_{j}\right) / M_{c}$ for all $c$. Then $(20)$ and the fact established above that $a_{R c}=a_{R}$ for all $c$ imply that $\kappa_{c}=\kappa=\theta_{K} C$. Clearly, $\kappa$ is independent of any $\theta_{\psi c}$ or $\tau_{j c}$.
} 
capital in country $c$, according to (19). Finally, as in Section 4.2, they may face or impose different trade barriers $\tau_{j c}$ and operate with different manufacturing productivities, $\theta_{\psi c}$. In all of these cases, (20) and (21) imply

$$
\frac{g_{M}}{\rho+g_{M}}=\frac{(1-s) \int_{a_{R c}}^{a_{\max }} T(a) d H(a)}{\Lambda\left(a_{R c}\right)} \text { for all } c .
$$

It is clear from (22) that, since all countries converge on the same long-run growth rate of varieties, they must also have the same ability cutoff level $a_{R c}=a_{R}$. Then, all share a common longrun wage profile. It is interesting to note that international integration generates a convergence in income inequality around the globe, whereas differences in innovation capacity give rise to different degrees of inequality in autarky.

Although relative wages are the same in all countries, wage levels are not equalized internationally. We show in Appendix 4.3, for example, that if intermediate goods are freely traded $\left(\tau_{j c}=1\right.$ for all $j$ and $c)$ and knowledge spillovers are complete $\left(\theta_{K j c}=\theta_{K c}\right.$ for all $\left.c\right)$, the relative wages of workers of any common ability level in countries $i$ and $j$ hinges on a comparison of $\theta_{K i} \theta_{T i}$ versus $\theta_{K j} \theta_{T j}$. The greater is the product of a country's research productivity and its efficiency in generating knowledge capital from global research experience, the greater is the level of its wages. If trade is not free, a country's size can also affect the level of its wages due to a home-market effect that expands market access for its producers.

Next observe that with $a_{R c}=a_{R}$ for all $c$, (20) implies that $\zeta_{c} \equiv \kappa_{c} N_{c} \theta_{T c}$ takes a common value across all countries, i.e., $\zeta_{c}=\zeta$ for all $c$. Substituting $\zeta$ into (19), we have

$$
\zeta \mu_{c}=\sum_{j=1}^{C} \gamma_{j c} \mu_{j}
$$

where $\gamma_{j c} \equiv \theta_{K j c} N_{c} \theta_{T c}$ captures innovation capacity in the open economy and $\mu_{c} \equiv M_{c} / \sum_{j} M_{j}$ is the share of country $c$ in the total number of varieties of intermediate goods in the world economy. We recognize $\zeta$ as being a characteristic root of the matrix $\boldsymbol{\Gamma}=\left\{\gamma_{j c}\right\}$, with associated characteristic vector $\boldsymbol{\mu}=\left\{\mu_{c}\right\}$. Moreover, by the assumption that $\theta_{K j c}>0$ for all $j$ and $c$, all elements of $\boldsymbol{\Gamma}$ are strictly positive. Then the Perron-Frobenius Theorem implies that all elements of $\boldsymbol{\mu}$ can be positive (as they must be) only if $\zeta$ is the largest characteristic root of $\boldsymbol{\Gamma}$. Finally, the envelope theorem implies that $\zeta$ must be increasing in every element $\gamma_{j c}$ of $\boldsymbol{\Gamma}{ }^{31}$

We have thus established that an increase in any spillover parameter $\theta_{K j c}$, in any country size $N_{c}$ or in any R\&D productivity parameter $\theta_{T c}$, shifts upward the $R R$ curve and the $A A$ curve for every country, and the former by more (at the initial $a_{R}$ ) than the latter. The result is an increase in the common rate of long-run growth and an increase in income inequality in every country.

${ }^{31}$ Multiplying the characteristic equation by $\mu_{c}$ and summing over all $c$ yields

$$
\zeta=\frac{\sum_{c=1}^{C} \sum_{j=1}^{C} \gamma_{j c} \mu_{j} \mu_{c}}{\sum_{c=1}^{C}\left(\mu_{c}\right)^{2}}
$$

The largest characteristic root is found by maximizing the right hand side with respect to $\left\{\mu_{c}\right\}$. By the envelope theorem, the largest $\zeta$ is an increasing function of every $\gamma_{j c}$. 
We record our findings in

Proposition 7 Suppose that intermediate goods are tradable and all countries have the same R\&D subsidy s. Then all countries grow at the same rate in a balanced-growth equilibrium and all have the same wage inequality in the long run. An increase in any spillover parameter $\theta_{K c}$, in any country size $N_{c}$ or in any RED productivity parameter $\theta_{T c}$ leads to faster growth and greater income inequality in every country.

\subsection{Differences in R\&D Subsidies}

Suppose that international knowledge spillovers are complete and that countries are similar in all ways except in their R\&D subsidies and in the proportional wage taxes used to finance these subsidies. $^{32}$ It is clear from (20) that, with $N_{c}=N$ and $\theta_{T c}=\theta_{T}$ for all $c$, convergence to a common long-run growth rate requires

$$
\kappa_{c}=\frac{\theta_{K} \sum_{j=1}^{C}\left[\int_{a_{R j}}^{a_{\max }} T(a) d H(a)\right]}{\int_{a_{R c}}^{a_{\max }} T(a) d H(a)} .
$$

That is, the ratio of the knowledge stock in country $c$ to that country's own cumulative experience in research mirrors the ratio of aggregate world allocation of labor to R\&D (adjusted for productivity) relative to the country's own allocation of labor to R\&D (adjusted for productivity). Under these circumstances, the long-run zero-profit conditions (21) vary across countries and therefore so too do the equilibrium cutoff levels.

Let us compare two countries $i$ and $j$ such that $s_{i}>s_{j}$; i.e., country $i$ supports research activities more generously than does country $j$. Substituting the expressions for $\kappa_{i}$ and $\kappa_{j}$ into (21), we find

$$
\frac{1-s_{i}}{1-s_{j}}=\frac{\Lambda\left(a_{R i}\right) / \int_{a_{R i}}^{a_{\max }} T(a) d H(a)}{\Lambda\left(a_{R j}\right) / \int_{a_{R j}}^{a_{\max }} T(a) d H(a)} .
$$

The right-hand side of this expression is increasing in $a_{R i}$ and decreasing in $a_{R j}$, so $s_{i}>s_{j}$ implies $a_{R i}<a_{R j}$; i.e., the research sector is larger as a fraction of the labor force in the country that promotes R\&D more aggressively. This does not generate faster long-run growth in $i$ than in $j$, but it does spell a more unequal long-run income distribution there.

Although wage profiles do not converge in the presence of (differential) R\&D subsidies, such policies do affect growth and inequality throughout the world. To examine these spillover effects of innovation policy, we treat (20) and (21) as a system of $C+1$ equations that determines the $C$ cutoff ability levels and the common growth rate, $g_{M}$. We prove in Appendix A4.4 that an increase in an arbitrary subsidy rate $s_{i}$ leads to an expansion of the research sectors in all countries. ${ }^{33}$ In other

\footnotetext{
${ }^{32}$ It is relatively easy to verify that the implications of differences in research support would be the same as we describe here, even if we allowed for cross-country differences in innovation capacity and in tariff rates. However, we assume that these features are common in order to simplify the exposition.

${ }^{33}$ The proof involves substituting (20) into the $C$ equations that comprise (21) and then totally log differentiating
} 
words, $d a_{R j} / d s_{i}<0$ for all $i, j \in\{1, \ldots, C\}$. It follows that an increase in a single subsidy rate contributes not only to faster innovation throughout the world economy, but also to a spreading of the long-run wage distribution everywhere. We summarize in

Proposition 8 Suppose that intermediate goods are tradable, that international knowledge spillovers are complete, and that countries differ only in their RED subsidy rates. Comparing any two countries, the long-run wage distribution is everywhere more unequal in the one with the greater subsidy rate. An increase in any subsidy rate raises the common long-run growth rate and generates a spread in the distribution of wages in every country.

\subsection{Differences in Technology Sets}

Our last comparison involves countries whose innovators draw from different technology sets. As in Section 3.4, we take $G_{c}(\varphi)$ to be a truncated Pareto distribution with shape parameter $k>2$ (common to all countries) and with a range in country $c$ given by $\left[\varphi_{\min }, \bar{\varphi}_{c}\right]$. In (21), we now write $\Lambda\left(a_{R c} ; \bar{\varphi}_{c}\right)$, to emphasize the fact that the upper limit of the technology distribution affects the matching between workers and technologies and thus the relative wage profile, $\lambda\left(a ; a_{R c}, \bar{\varphi}_{c}\right)$. Note, however, that if two countries share the same ability cutoff and the same maximum technology level, they will have the same matching and wage profiles in manufacturing; i.e., $\lambda(\cdot)$ and $\Lambda(\cdot)$ take the same forms in all countries, given $\bar{\varphi}_{c}$.

Suppose that international knowledge spillovers are complete, that countries are equal in size $\left(N_{c}=N\right)$, have the same R\&D productivity $\left(\theta_{T c}=\theta_{T}\right.$ for all $\left.c\right)$, have the same capacity to convert the global knowledge stock into usable knowledge capital $\left(\theta_{K c}=\theta_{K}\right.$ for all $\left.c\right)$ and impose the same $\mathrm{R} \& \mathrm{D}$ subsidies $\left(s_{c}=s\right.$ for all $\left.c\right)$. In these circumstances, if the countries differ with respect to $\bar{\varphi}_{c}$, convergence in growth rates again requires

$$
\kappa_{c}=\frac{\theta_{K} \sum_{j=1}^{C}\left[\int_{a_{R j}}^{a_{\max }} T(a) d H(a)\right]}{\int_{a_{R c}}^{a_{\max }} T(a) d H(a)},
$$

just as in the case with differential R\&D subsidies. Substituting this value of $\kappa_{c}$, and $\Lambda\left(a_{R c} ; \bar{\varphi}_{c}\right)$, into (21), and using the assumption that R\&D subsidies are common across all countries, we see that the cutoff ability levels cannot be the same in countries where innovators draw from different productivity sets. In fact, $\kappa_{c} \Lambda\left(a_{R c} ; \bar{\varphi}_{c}\right)$ is increasing in $a_{R c}$ but decreasing in $\bar{\varphi}_{c}$, so a country that draws from a better set of production technologies has a larger value of $a_{R c}$, thus a larger manufacturing sector and a smaller R\&D sector. All countries grow at the same rate along the balanced growth-path, as growth is driven by the accumulation of global knowledge capital.

the result with respect to the vector of net-of-subsidy elements $\left\{1-s_{c}\right\}$ and finding the matrix $\mathbf{A}_{s}$ that pre-multiplies the vector $\left\{d a_{R c} / a_{R c}\right\}$ in the resulting system. We show that $\mathbf{A}_{s}$ has positive diagonal elements and negative offdiagonal elements and that there exists a diagonal matrix $\mathbf{D}_{s}$ such that $\mathbf{A}_{s} \mathbf{D}_{s}$ is diagonally dominant of its rows (i.e., the row sum is positive for each row). This implies that $\mathbf{A}_{s}$ is an M-matrix (Johnson, 1982) and therefore the inverse matrix $\mathbf{A}_{s}^{-1}$ has only positive elements. 
In the long run, income inequality differs systematically across countries. On the one hand, a better set of technologies implies better matching opportunities for workers in the manufacturing sector. On the other hand, the induced change in the composition of workers in manufacturing intensifies the competition for the good technologies. But by arguments similar to those used to prove Proposition 4, it turns out that the former force must dominate. If $\bar{\varphi}_{i}>\bar{\varphi}_{j}$, then $a_{R i}>a_{R j}$ and so a manufacturing worker of given ability in country $i$ finds a better technology match than his counterpart of similar ability in country $j$. Consequently, manufacturing wages are less equally distributed in country $i$ than in country $j$. However, the manufacturing sector is larger in country $i$ than in country $j$, so a smaller set of workers enjoy the higher returns to ability that research work affords. Overall, inequality in country $i$ is greater than that in country $j$ for individuals with ability $a<a_{R j}$, but inequality is at least as great in country $j$ as in country $i$ for individuals with $a>a_{R j}$. Finally, as in autarky, there are workers in the middle of the ability distribution in country $i$ who earn more relative to both the most able and least able of their countryman than do their counterparts of similar ability in country $j$. We record

Proposition 9 Suppose that intermediate goods are tradable, that international knowledge spillovers are complete, and that countries differ only in the technology sets from which their inventors draw. If $G_{c}(\varphi)$ is a truncated Pareto distribution with shape parameter $k>2$ and with a range in country c given by $\left[\varphi_{\min }, \bar{\varphi}_{c}\right]$ and if $\bar{\varphi}_{i}>\bar{\varphi}_{j}$, then inequality in country $i$ is greater than that in country $j$ for workers with ability $a<a_{R j}$, but inequality is at least as great in country $j$ as in country $i$ for workers with ability $a>a_{R j}$. There exists a range of abilities $\mathcal{A}=\left[a^{*}, a^{* *}\right]$ such that for $a \in \mathcal{A}$, $w_{i}(a) / w_{i}\left(a_{\min }\right)>w_{j}(a) / w_{j}\left(a_{\min }\right)$ and $w_{i}(a) / w_{i}\left(a_{\max }\right)>w_{j}(a) / w_{j}\left(a_{\max }\right)$.

The main lessons from this section are threefold. First, international integration affords researchers access to a larger knowledge stock, which raises research productivity worldwide and leads to an acceleration of innovation and growth. At the same time, the expansion of each country's idea-generating sector spells a ubiquitous increase in wage inequality. Second, national conditions that create differential incentives for research versus manufacturing generate long-run differences in wage distributions, whereas conditions that affect a country's ability to contribute to or draw on the world's stock of knowledge capital lead to a convergence in wage distributions but with crosscountry differences in wage levels. Finally, technological conditions or government policies that cause an expansion of the research sector in one country typically have spillover effects abroad. In particular, when the incentives for $R \& D$ rise somewhere, the induced expansion in knowledge capital generates a positive growth spillover for other countries and a tendency for income inequality to rise everywhere.

\section{Concluding Remarks}

In this paper, we have studied in depth one mechanism that links long-run growth and income distribution. The mechanism operates via sorting and matching in the labor market. We posit 
that the most able individuals in any economy specialize in creating ideas and that innovation is the engine of growth. Among those that use ideas rather than create them, a complementarity between ability and technology dictates matching between the more able individuals and the more sophisticated and productive technologies. In the long run, the size of what we call the research sector determines not only the pace of innovation, but also the composition of the manufacturing sector and therefore the matching between workers and technologies that results.

We have explored this mechanism in a very simple economic environment. We have abstracted from diversity in manufacturing industries, from team production activities that involve multiple individuals in both research and manufacturing, from capital inputs that may be complementary to certain worker or inventor types, and from a host of market frictions that can impede job placement and financing for innovation. Nonetheless, we have been able to shed light on a rich set of interactions between growth and inequality. Typically, but not ubiquitously, faster growth goes hand in hand with greater inequality; a larger research sector spells higher returns for the most able individuals in the economy as well as better technological matches for workers in the (smaller) manufacturing sector, which tends to favor especially those manufacturing workers that are more able and better paid. We have identified technological and policy features of the economy that affect long-run inequality and others that affect only levels of income but not relative compensation.

By allowing for international trade and international knowledge spillovers, we introduced links between inequality measures in different countries. Generally, we find that within-country income inequality is exacerbated by globalization. The mechanism is not the usual one, however, i.e., that trade leads to specialization in sectors that differ in factor intensity, but rather that international knowledge sharing makes innovation more productive and so creates incentives for expansion of the idea-generating portion of the economy worldwide. As the research sector expands in every country so too does the relative pay for the most able individuals (who engage in innovation) as well as for the more able workers that sort to manufacturing. As a rule, the more able workers in manufacturing benefit relatively more from the improved matching with technologies. Our treatment of the open economy also allows us to study the links between conditions and policies in one country and growth and distributional outcomes in its trade partners. For example, we find that an $R \& D$ subsidy in one country accelerates growth in all countries and increases within-country income inequality throughout the globe. While previous work on endogenous growth emphasized crosscountry dependence in growth rates (e.g., Grossman and Helpman 1991), our model also features cross-country dependence in wage inequality. Moreover, while long-run growth rates converge, cross-country differences in wage inequality can persist even along a balanced-growth path.

Numerous possible extensions of our model come to mind. Additional elements of interdependence would arise if production functions involved multiple factors of production (or teams of individuals) and if sectors differed in their relative factor intensities. We also suspect that investment in ideas has more dimensions of uncertainty than just the productivity of the resulting technology, and that the prospects for success in innovation and the range of reachable technologies depend on the abilities of the individuals who generate the new ideas. Imperfect information about 
worker characteristics and frictions in labor markets undoubtedly impede the smooth, assortative matching that features in our model. Similarly, asymmetric information about research ideas and financing constraints impede investment in innovation and bias technological outcomes. All of these extensions would be interesting.

We view our contribution in this paper not as a final word on the link between growth and inequality, but as an exploration of a core mechanism that will play a role in richer economic environments. The empirical importance of this mechanism remains to be settled, although at this stage it is not obvious how to do so in light of the limited availability of historical data and the endogeneity of the variables of interest. 


\section{References}

[1] Alesina, Alberto and Rodrik, Dani, 1994. "Distributive Politics and Economic Growth," Quarterly Journal of Economics 109(2), 465-490.

[2] Atkinson, Anthony B., Piketty, Thomas, and Saez, Emmanual, 2011. "Top Incomes in the Long Run of History," Journal of Economic Literature 49(1), 3-71.

[3] Autor, David, 2010. The Polarization of Job Opportunities in the U.S. Labor Market: Implications for Employment and Earnings (Washington DC: Center for American Progress and The Hamilton Project).

[4] Bourguignon, François J. and Morrisson, Christian, 2002. "Inequality Among World Citizen, 1820-1992," American Economic Review, 92(4), 727-44.

[5] Coe, David T., Helpman, Elhanan, and Hoffmaister, Alexander W., 2009. "International R\&D Spillovers and Institutions," European Economic Review, 53(7), 723-41.

[6] Costinot, Arnaud, 2009. "An Elementary Theory of Comparative Advantage," Econometrica $77(4), 1165-92$.

[7] Eeckhout, Jan and Kircher, Philipp, 2012. "Assortative Matching with Large Firms: Span of Control over More versus Better Workers." Downloadable at http://personal.lse.ac.uk/kircher/Papers/sorting-and-factor-intensity.pdf.

[8] Galor, Oded and Zeira, Joseph, 1993. "Income Distribution and Macroeconomics," The Review of Economic Studies 60(1), 35-52.

[9] Grossman, Gene M. and Helpman, Elhanan, 1991. Innovation and Growth in the Global Economy (Cambridge MA: The MIT Press).

[10] Grossman, Gene M., Helpman, Elhanan, and Kircher, Phillip, 2013. "Matching and Sorting in the Global Economy," National Bureau of Economic Research Working Paper No. 19513.

[11] Helpman, Elhanan, 2004. The Mystery of Economic Growth (Cambridge MA: Belknap by Harvard University Press).

[12] Johnson, Charles R., 1982. "Inverse M-Matrixes," Linear Algebra and its Applications 47(C), 195-216.

[13] Kaldor, Nicholas, 1955-56. "Alternative Theories of Distribution," The Review of Economic Studies 23(2), 83-100.

[14] Kopczuk, Wojciech, Saez, Emanuel and Song, Jae, 2010. "Earnings Inequality and Mobility in the United States: Evidence from Social Security Data Since 1937," Quarterly Journal of Economics 125(1), 91-128. 
[15] Kuznets, Simon, 1955. "Economic Growth and Income Inequality," American Economic Review 45(1), 1-28.

[16] Kuznets, Simon, 1963. "Quantitative Aspects of the Economic Growth of Nations: VIII. Distribution of Income by Size," Economic Development and Cultural Change 11(2:2), 1-80.

[17] Maddison, Angus, 2001. The World Economy: A Millenial Perspective (Paris: OECD).

[18] Melitz, Marc J., 2003. "The Impact of Trade on Intra-Industry Reallocations and Aggregate Industry Productivity," Econometrica 71(6), 1695-1725.

[19] Morrisson, Christian and Murtin, Fabrice, 2011a. "Average Income Inequality between Countries (1700-2030)," Fondation pour les Études et Recherches sur le Développement International Working Paper No. 25.

[20] Morrisson, Christian and Murtin, Fabrice, 2011b. "Internal Income Inequality and Global Inequality," Fondation pour les Études et Recherches sur le Développement International Working Paper No. 26.

[21] Persson, Torsten and Tabellini, Guido, 1994. "Is Inequality Harmful for Growth," American Economic Review 84(3), 600-621.

[22] Redding, Stephen and Venables, Anthony, 2004. "Economic Geography and International Inequality," Journal of International Economics 62(1), 53-82.

[23] Romer, Paul M., 1990. "Endogenous Technical Change," Journal of Political Economy 98(5:2), 71-102.

[24] Sala-i-Martin, Xavier, 2006. "The World Distribution of Income: Falling Poverty and ...Convergence, Period," Quarterly Journal of Economics 121(2), 351-97. 


\section{Appendix}

\section{A2.4 Uniqueness and Single Crossing of Matching Function}

In Section 2.4 we stated that the solution to the pair of differential equations (11) and (13) that satisfies the boundary conditions (14) is unique, and later that the matching functions of two solutions to (11) and (13) that apply for different boundary conditions can intersect at most once. Here, we prove these statements by adapting Lemma 2 in the appendix of Grossman et al. (2013) to the current circumstances.

We begin with the latter claim. As in Grossman et al. (2013), let $\left[m_{\varkappa}(\varphi), w_{\varkappa}(a)\right]$ and $\left[m_{\varrho}(\varphi), w_{\varrho}(a)\right]$ be solutions to the differential equations (11) and (13), each for different boundary conditions,

$$
m\left(\varphi_{\min }\right)=a_{z, \min } \text { and } m\left(\varphi_{\max }\right)=a_{z, \max }, z=\varkappa, \varrho .
$$

Let the solutions intersect for some $\varphi=\varphi_{0}$ and $a=a_{0}$. Without loss of generality, suppose that $m_{\varrho}^{\prime}\left(\varphi_{0}\right)>$ $m_{\varkappa}^{\prime}\left(\varphi_{0}\right)$. We will now show that $m_{\varrho}(\varphi)>m_{\varkappa}(\varphi)$ for all $\varphi>\varphi_{0}$ and $m_{\varrho}(\varphi)<m_{\varkappa}(\varphi)$ for all $\varphi<\varphi_{0}$ in the overlapping set of $(\varphi, a)$.

To see this, suppose to the contrary there exists a $\varphi_{1}>\varphi_{0}$ such that $m_{\varrho}\left(\varphi_{1}\right) \leq m_{\varkappa}\left(\varphi_{1}\right)$. Then differentiability of $m_{z}(\cdot), z=\varkappa, \varrho$, implies that there exists a $\varphi_{2}$ with $\varphi_{2}>\varphi_{0}$ such that $m_{\varrho}\left(\varphi_{2}\right)=m_{\varkappa}\left(\varphi_{2}\right)$, $m_{\varrho}(\varphi)>m_{\varkappa}(\varphi)$ for all $\varphi \in\left(\varphi_{0}, \varphi_{2}\right)$ and $m_{\varrho}^{\prime}\left(\varphi_{2}\right)<m_{\varkappa}^{\prime}\left(\varphi_{2}\right)$. This also implies that $m_{\varrho}^{-1}(a)<m_{\varkappa}^{-1}(a)$ for all $a \in\left(m_{\varrho}\left(\varphi_{0}\right), m_{\varrho}\left(\varphi_{2}\right)\right)$, where $m_{z}^{-1}(\cdot)$ is the inverse of $m_{z}(\cdot)$. But then (13) implies that $w_{\varrho}\left[m_{\varrho}\left(\varphi_{0}\right)\right]<w_{\varkappa}\left[m_{\varrho}\left(\varphi_{0}\right)\right]$ and $w_{\varrho}\left[m_{\varrho}\left(\varphi_{2}\right)\right]>w_{\varkappa}\left[m_{\varrho}\left(\varphi_{2}\right)\right]$, and therefore

$$
\ln w_{\varkappa}\left[m_{\varrho}\left(\varphi_{2}\right)\right]-\ln w_{\varkappa}\left[m_{\varrho}\left(\varphi_{0}\right)\right]<\ln w_{\varrho}\left[m_{\varrho}\left(\varphi_{2}\right)\right]-\ln w_{\varrho}\left[m_{\varrho}\left(\varphi_{0}\right)\right]
$$

On the other hand, (11) implies that

$$
\ln w_{z}\left[m_{\varrho}\left(\varphi_{2}\right)\right]-\ln w_{z}\left[m_{\varrho}\left(\varphi_{0}\right)\right]=\int_{m_{\varrho}\left(\varphi_{0}\right)}^{m_{\varrho}\left(\varphi_{2}\right)} \frac{\psi_{a}\left[m_{z}^{-1}(a), a\right]}{\psi\left[m_{z}^{-1}(a), a\right]} d a, \quad z=\varkappa, \varrho .
$$

Together with the previous inequality, this gives

$$
\int_{m_{\varrho}\left(\varphi_{0}\right)}^{m_{\varrho}\left(\varphi_{2}\right)} \frac{\psi_{a}\left[m_{\varkappa}^{-1}(a), a\right]}{\psi\left[m_{\varkappa}^{-1}(a), a\right]} d a<\int_{m_{\varrho}\left(\varphi_{0}\right)}^{m_{\varrho}\left(\varphi_{2}\right)} \frac{\psi_{a}\left[m_{\varrho}^{-1}(a), a\right]}{\psi\left[m_{\varrho}^{-1}(a), a\right]} d a .
$$

Note, however, that strict $\log$ supermodularity of $\psi(\cdot)$ and $m_{\varrho}^{-1}(a)<m_{\varkappa}^{-1}(a)$ for all $a \in\left(m_{\varrho}\left(\varphi_{0}\right), m_{\varrho}\left(\varphi_{2}\right)\right)$ imply the reverse inequality, which establishes a contradiction. It follows that $m_{\varrho}(\varphi)>m_{\varkappa}(\varphi)$ for all $\varphi>\varphi_{0}$. A similar argument shows that $m_{\varrho}(\varphi)<m_{\varkappa}(\varphi)$ for all $\varphi<\varphi_{0}$.

The fact that the matching functions for different boundary conditions can cross at most once immediately implies the uniqueness of the solution to (11) and (13) for a given set of boundary conditions, $m\left(\varphi_{\min }\right)=a_{\min }$ and $m\left(\varphi_{\max }\right)=a_{R}$. If there were two different solutions for these boundary conditions, the resulting matching functions would have to intersect at least twice, which is not possible. 


\section{A2.5 The $A A$ Curve}

In this appendix, we derive the equation for the $A A$ curve and establish that it is upward sloping.

We use the labor-market clearing condition (12) for $\varphi=\varphi_{\max }$. After substituting the boundary condition $m\left(\varphi_{\max }\right)=a_{R}$ and the definition of the relative-wage function $\lambda\left(a ; a_{R}\right)=w\left(a ; a_{R}\right) / w\left(a_{\min } ; a_{R}\right)$ into this equation, we obtain

$$
M X\left(\frac{\sigma}{\sigma-1}\right)^{-\sigma} \int_{\varphi_{\min }}^{\varphi_{\max }} \frac{\lambda\left[m\left(\varphi ; a_{R}\right) ; a_{R}\right]^{1-\sigma}}{\psi\left[\varphi, m\left(\varphi ; a_{R}\right)\right]^{1-\sigma}} d G(\varphi)=w\left(a_{\min } ; a_{R}\right)^{\sigma} N \int_{a_{\min }}^{a_{R}} \lambda\left(a ; a_{R}\right) d H(a) .
$$

Now combine (24) with the free-entry condition (10), then (8) and the fact that the wage schedule is continuous at $a_{R}$ to derive $\rho+g_{M}=\theta_{K} N \Lambda\left(a_{R}\right)$, where

$$
\Lambda\left(a_{R}\right) \equiv \frac{T\left(a_{R}\right)}{(\sigma-1) \lambda\left(a_{R} ; a_{R}\right)} \int_{a_{\min }}^{a_{R}} \lambda\left(a ; a_{R}\right) d H(a) .
$$

Now, (log) differentiating the expression for $\Lambda\left(a_{R}\right)$ gives

$$
\frac{\Lambda^{\prime}\left(a_{R}\right)}{\Lambda\left(a_{R}\right)}=\frac{H^{\prime}\left(a_{R}\right)}{\int_{a_{\min }}^{a_{R}} \frac{\lambda\left(a_{0} a_{R}\right)}{\lambda\left(a_{R} ; a_{R}\right)} d H(a)}+\left[\frac{T^{\prime}\left(a_{R}\right)}{T\left(a_{R}\right)}-\frac{\lambda_{1}\left(a_{R} ; a_{R}\right)}{\lambda\left(a_{R} ; a_{R}\right)}\right]+\left.\frac{\Lambda_{1}^{\prime}(b)}{\Lambda_{1}(b)}\right|_{b=a_{R}},
$$

where $\lambda_{1}(a ; b)$ is the partial derivative of $\lambda(a ; b)$ with respect to $a$ and

$$
\Lambda_{1}(b) \equiv \int_{a_{\min }}^{a_{R}} \frac{\lambda(a ; b)}{\lambda\left(a_{R} ; b\right)} d H(a)=\int_{a_{\min }}^{a_{R}} \frac{w(a ; b)}{w\left(a_{R} ; b\right)} d H(a) .
$$

In this representation, $\Lambda_{1}(b)$ is the integral of the wage ratios at $a$ and $a_{R}$, weighted by the density $H^{\prime}(a)$, when the cutoff is $b$. Naturally, this expression applies only for $b \geq \max \left\{a, a_{R}\right\}$.

Next note that the first term on the right-hand side of (25) is positive. The second term also is positive, because Assumption 2 that ensures the sorting of the most able individuals into R\&D and the continuity of the wage schedule at $a_{R}$. To sign the third term, observe that (11) implies

$$
\ln w\left(a_{1} ; a_{R}\right)-\ln w\left(a_{2} ; a_{R}\right)=\int_{a_{2}}^{a_{1}} \frac{\psi_{a}\left[m^{-1}\left(v ; a_{R}\right), v\right]}{\psi\left[m^{-1}\left(v ; a_{R}\right), v\right]} d v \text { for all } a_{1}, a_{2} \in\left[a_{\min }, a_{R}\right]
$$

and therefore

$$
\frac{w(a ; b)}{w\left(a_{R} ; b\right)}=\exp \left\{-\int_{a}^{a_{R}} \frac{\psi_{a}\left[m^{-1}(v ; b), v\right]}{\psi\left[m^{-1}(v ; b), v\right]} d v\right\},
$$

where $m^{-1}(v ; b)$ is the inverse matching function when the highest ability worker in manufacturing is $b$. An increase in $b$ reduces the quality of matches for all workers in manufacturing and therefore reduces $m^{-1}(v ; b)$ for all ability levels, $v$. The log supermodularity of the productivity function dictated by Assumption 1 then implies that $\psi_{a}\left[m^{-1}(v ; b), v\right] / \psi\left[m^{-1}(v ; b), v\right]$ declines for all $v$ and, therefore, that $w(a ; b) / w\left(a_{R} ; b\right)$ increases for all $a<a_{R}$. It follows that $\Lambda_{1}(b)$ is increasing for all $b$, including for $b \rightarrow a_{R}$. Hence the third term on the right-hand side of (25) also is positive. We have thus shown that $\Lambda^{\prime}\left(a_{R}\right)>0$. 


\section{A4.3 Cross-Country Wage Levels with Differences in Innovation Capacity}

Here we consider the cross-country differences in wage levels that result from asymmetries in innovation capacity. We assume equal R\&D subsidy rates and complete international knowledge spillovers; i.e., $s_{j}=s$ and $\theta_{K j c}=\theta_{K c}$ for all $j$. Note that this allows for international differences in capacities to convert knowledge capital into new varieties, as captured by $\theta_{K c}$. We also allow for differences in country size, $N_{c}$, and for differences in research productivity, $\theta_{T c}$.

We have seen in Section 4.3 that, with differences in innovation capacity, the cutoff ability levels $a_{R c}$ are the same in all countries, and so therefore are the distributions of wages. We represent the wage schedule in country $c$ by $w_{c}(a)=\omega_{c} w(a)$ and refer to $\omega_{c}$ as the wage level in country $c$.

Substituting the expression for profits analogous to (8) that applies to the open economy into the freeentry condition analogous to (10) that does likewise, and taking the ratio of the resulting equations that hold for two countries $i$ and $j$, we find

$$
\frac{\omega_{i}^{1-\sigma} \bar{X}_{i}}{\omega_{j}^{1-\sigma} \bar{X}_{j}}=\frac{\omega_{i}}{\theta_{K i} \theta_{T i}} \frac{\theta_{K j} \theta_{T j}}{\omega_{j}}
$$

or

$$
\frac{\omega_{i}}{\omega_{j}}=\left(\frac{\theta_{K i} \theta_{T i} \bar{X}_{i}}{\theta_{K j} \theta_{T j} \bar{X}_{j}}\right)^{1 / \sigma}
$$

If intermediate goods are freely trade $\left(\tau_{j c}=1\right.$ for all $j$ and $\left.c\right)$, then $\bar{X}_{c}=\bar{X}=\sum_{j=1}^{C} X_{j}$; i.e., market access is the same in all countries. Under these circumstances, (26) implies that the relative wage levels in any pair of countries $i$ and $j$ varies monotonically with $\left(\theta_{K i} \theta_{T i}\right) /\left(\theta_{K j} \theta_{T j}\right)$ and does not depend on their relative size, $N_{i} / N_{j}$. If, on the other hand, there exist barriers to trade, then market access will not be the same in all countries. With equal trade barriers $\tau_{j c}=\tau>1$ for $j \neq c$, a home-market effect would generate a greater market access for larger countries and therefore higher wages.

\section{A4.4 Spillover Effects of National R\&D Subsidies}

In this appendix, we examine the effects of changing an R\&D subsidy in one country on growth and inequality in that country and in all trading partners.

As in Section 4.4, we suppose that international knowledge spillovers are complete and that countries are similar in all ways except in their $R \& D$ subsidies and in the proportional wage taxes used to finance these subsidies. Under these circumstances, (20) implies

$$
\kappa_{c}=\frac{\theta_{K} \sum_{j=1}^{C} \int_{a_{R j}}^{a_{\max }} T(a) d H(a)}{\int_{a_{R c}}^{a_{\max }} T(a) d H(a)} .
$$

Substituting for $\kappa_{c}$ in (20) and (21), and then substituting the former equation into the latter, we can reduce the set of equilibrium conditions to the following system of $C$ equations in the $C$ unknowns, $a_{R c}$ :

$$
\left(1-s_{c}\right) \frac{\rho+\theta_{K} N \theta_{T} \sum_{j=1}^{C} \int_{a_{R j}}^{a_{\max }} T(a) d H(a)}{\theta_{K} N \theta_{T} \sum_{j=1}^{C} \int_{a_{R j}}^{a_{\max }} T(a) d H(a)} \int_{a_{R c}}^{a_{\max }} T(a) d H(a)=\Lambda\left(a_{R c}\right) \text { for all } c .
$$


Now we proportionately differentiate this system of equations and write the (matrix) equation for the proportional changes as

$$
\mathbf{A}_{s} \mathbf{a}_{s}=\mathbf{b}_{s}
$$

where

$$
\mathbf{a}_{s}=\left(\begin{array}{c}
\hat{a}_{R 1} \\
\hat{a}_{R 2} \\
\cdot \\
\cdot \\
\cdot \\
\hat{a}_{R C}
\end{array}\right), \quad \mathbf{b}_{s}=\left(\begin{array}{c}
\left(\widehat{1-s_{1}}\right) \\
\left(\widehat{1-s_{2}}\right) \\
\cdot \\
\cdot \\
\cdot \\
\left(\widehat{1-s_{C}}\right)
\end{array}\right)
$$

and a "hat" over a variable represents a proportional rate of change; i.e., $\hat{a}_{R c}=d a_{R c} / a_{R c}$ and $\left(\widehat{1-s_{c}}\right)=$ $d\left(1-s_{c}\right) /\left(1-s_{c}\right)$.

We note that the matrix $A_{s}$ has positive diagonal elements and negative off-diagonal elements. In particular, in row $j$, the diagonal element is $\varepsilon_{\Lambda j}+\left(1-\eta_{j}\right) \varepsilon_{R j}$, where $\varepsilon_{\Lambda j}>0$ is the elasticity of $\Lambda(\cdot)$ evaluated at $a_{R j}, \varepsilon_{R j}>0$ is minus the elasticity of $\int_{a_{R}}^{a_{\max }} T(a) d H(a)$ with respect to $a_{R}$ evaluated at $a_{R j}$, and

$$
\eta_{j}=\left[\frac{\rho}{\rho+\theta_{K} N \sum_{i=1}^{C} \int_{a_{R i}}^{a_{\max }} T(a) d H(a)}\right]\left(\frac{M_{j}}{M}\right)<1 .
$$

For $j \neq c$, the off-diagonal element in column $j$ is $-\eta_{j} \varepsilon_{R j}<0$.

Inasmuch as $A_{s}$ has only negative off-diagonal elements, we recognize that it is a $Z$-matrix. Moreover, there exists a diagonal matrix $D_{s}$ such that $A_{s} D_{s}$ is diagonally dominant in its rows. To see this, consider the diagonal matrix $D_{s}$ that has a diagonal entry in row $j$ given by $1 / \varepsilon_{R j}$. Then the diagonal element in row $c$ and column $c$ of $A_{s} D_{s}$ is given by $\varepsilon_{\Lambda c} / \varepsilon_{R c}+\left(1-\eta_{c}\right)$ and the off-diagonal element in row $c$ and column $j$ is given by $-\eta_{j}$. Summing the entries in any row $c$ gives $\varepsilon_{\Lambda c} / \varepsilon_{R c}+1-\sum_{j=1}^{C} \eta_{j}>0$, where the inequality follows from the fact that $\sum_{j=1}^{C} \eta_{j}<1$.

Having established that $A_{s}$ is a $Z$-matrix and there exists a diagonal matrix $D_{s}$ such that $A_{s} D_{s}$ is diagonally dominant in its rows, it follows that $A_{s}$ is an $M$-matrix (see Johnson, 1982). Then its inverse, $A_{s}^{-1}$, has only positive elements. We conclude that an increase in any subsidy rate (i.e., a reduction in any $1-s_{c}$ ) reduces every cutoff point $a_{R j}, j=1, \ldots, C$. Since more individuals are hired as researchers in every country, every country grows faster and experiences greater income inequality. 